\title{
Agonist-Dependent Modulation of Cell Surface Expression of the Cold Receptor TRPM8
}

\author{
Carlos A. Toro, ${ }^{1,3 \star}$ Stephanie Eger, ${ }^{4,5 *}$ Luis Veliz, ${ }^{1}$ Pamela Sotelo-Hitschfeld, ${ }^{1,3}$ Deny Cabezas, ${ }^{1}$ Maite A. Castro, ${ }^{2}$ \\ Katharina Zimmermann, ${ }^{4,5}$ and ${ }^{\circledR S e b a s t i a n}$ Brauchi $^{1}$ \\ ${ }^{1}$ Instituto de Fisiología, Facultad de Medicina, ${ }^{2}$ Instituto de Bioquimica y Microbiologia, and ${ }^{3}$ Escuela de Graduados, Facultad de Ciencias, Universidad \\ Austral de Chile, Valdivia, Chile, ${ }^{4}$ Klinik für Anästhesiologie, Universitätsklinikum Erlangen, Friedrich-Alexander Universität Erlangen-Nürnberg, \\ Erlangen, Germany, and ${ }^{5}$ Institut für Physiologie und Pathophysiologie, Friedrich-Alexander Universität Erlangen-Nürnberg, Erlangen, Germany
}

The spatial and temporal distribution of receptors constitutes an important mechanism for controlling the magnitude of cellular responses. Several members of the transient receptor potential (TRP) ion channel family can regulate their function by modulating their expression at the plasma membrane (PM) through rapid vesicular translocation and fusion. The mechanisms underlying this regulation are not completely understood, and the contribution of vesicular trafficking to physiological function is unknown. TRPM8 receptors are expressed in mammalian peripheral sensory neurons and are essential for the detection of cold temperatures. Previously, we showed that TRPM8-containing vesicles are segregated into three main pools, immobile at the PM, simple diffusive and corralled-hopping. Here, we show that channel expression at the PM is modulated by TRPM8 agonists in F11 and HEK293T cells. Our results support a model in which the activation of TRPM8 channels, located at the PM, induces a short-lived recruitment of a TRPM8-containing vesicular pool to the cell surface causing a transitory increase in the number of functional channels, affecting intrinsic properties of cold receptor responses. We further demonstrate the requirement of intact vesicular trafficking to support sustained cold responses in the skin of mice.

Key words: cold; diffusion; peripheral sensory neurons; skin nerve preparation; vesicle; Botulinum neurotoxin Type A (BoNTA)

\section{Introduction}

In mammals, environmental changes in temperature are detected by specialized neurons of the somatosensory system whose somata reside in the dorsal root or trigeminal ganglia, innervating all peripheral tissues (Belmonte et al., 2009). The cold and menthol receptor transient receptor potential melastatin 8 (TRPM8) is responsible for the detection of environmental cold in mice (McKemy et al., 2002; Bautista et al., 2007; Dhaka et al., 2007). Biophysical studies show that TRPM8 channels are allosteric proteins integrating multiple channel-activating signals (e.g., cold, menthol, and voltage), trans-

Received Sept. 6, 2013; revised Sept. 22, 2014; accepted 0ct. 20, 2014.

Author contributions: C.A.T., S.E., D.C., M.A.C., K.Z., and S.B. designed research; C.A.T., S.E., D.C., P.S.-H., K.Z., and S.B. performed research; L.V., M.A.C., K.Z., and S.B. contributed unpublished reagents/analytic tools; C.A.T., S.E., L.V., D.C., P.S.-H., K.Z., and S.B. analyzed data; C.A.T., K.Z., and S.B. wrote the paper.

This work was supported by Fondo Nacional de Desarrollo Científico y Tecnológico Grants 11070190 and 1110906 to S.B., Grant 1110571 to M.A.C., and Deutsche Forschungsgemeinschaft Grants ZI 1172/2-1, ZI 1172/3-1, and ZI 1172/4-1 to K.Z., C.A.T. and P.S.-H. are Comisión Nacional de Investigación Científica y Tecnológica fellows. The S.B. laboratory is part of CISNe-UACh and UACh Program in Cellular Dynamics and Microscopy. The SchirmerVermächtnis-Stiftung at Friedrich-Alexander University Erlangen-Nürnberg awarded a travel grant to S.B. We thank the members of the S.B. laboratory and Peter W. Reeh for their thoughtful contributions; and Dr. C.P. Toro for critical reading of the final manuscript.

The authors declare no competing financial interests.

${ }^{*}$ C.A.T. and S.E. contributed equally to this work.

Correspondence should be addressed to either Dr. Sebastian Brauchi, Instituto de Fisiología, Facultad de Medicina, Universidad Austral de Chile, Valdivia, Chile, E-mail: sbrauchi@uach.cl; or Dr. Katharina Zimmermann, Klinik für Anästhesiologie, Universitätsklinikum Erlangen, Friedrich-Alexander Universität Erlangen-Nürnberg, Erlangen, Germany. E-mail. katharina.zimmermann@fau.de.

DOI:10.1523/JNEUROSCI.3820-13.2015

Copyright $\odot 2015$ the authors $\quad 0270-6474 / 15 / 350571-12 \$ 15.00 / 0$ ducing these stimuli into membrane depolarization via calcium and sodium permeation (Brauchi et al., 2004; Fernández et al., 2011).

The tight control over channel trafficking is a critical process in the regulation of the information flow, necessary to accurately transduce sensory stimuli. In addition to their presence at the plasma membrane (PM), a number of TRP channels are commonly localized to intracellular vesicles, and regulated exocytosis has been reported to control several TRP channel-mediated currents (Cayouette and Boulay, 2007; Toro et al., 2011). Insertion of vesicles containing TRPs into the PM can alter current amplitude by regulating the number of functional channels at the cell surface, as demonstrated for TRPV2 (Kanzaki et al., 1999), TRPC5 (Bezzerides et al., 2004), TRPC6 (Cayouette et al., 2004), TRPV1 (Zhang et al., 2005; Stein et al., 2006), TRPM7 (Oancea et al., 2006), TRPV5 (Lambers et al., 2007), TRPA1 (Schmidt et al., 2009), TRPM4 (Crnich et al., 2010), and TRPM8 (Veliz et al., 2010). It is clear that vesicular trafficking plays a key role in TRP-dependent cell responses; however, we do not understand the mechanisms associated with the dynamic control of TRP channel density at the PM, or the consequence of this phenomenon at the physiological level.

We recently reported that TRPM8-transporting vesicles undergo distinct patterns of movement in, or very near, $\mathrm{PM}$ regions (Veliz et al., 2010). This dynamic behavior results in vesicle dwelling times up to a few seconds within defined regions of the PM we interpreted as membrane corrals (Veliz et al., 2010). It has been reported that targeting of TRPM8 channels to cholesterol-rich membrane domains, together with post-translational modifica- 

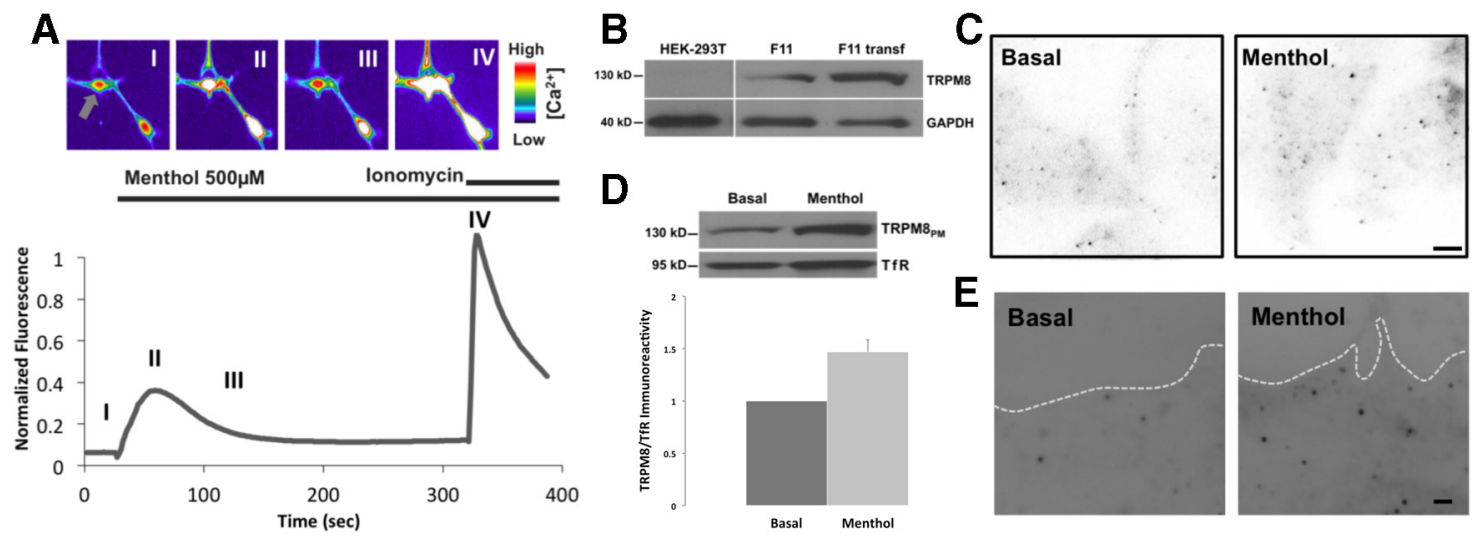

Figure 1. Functional endogenous TRPM8 channels are expressed in DRG-derived F11 cells and upregulated after menthol treatment. $A$, Calcium indicator fluorescence intensity of representative F11 cells in the presence of TRPM8 agonist. False color images of F11 cells loaded with Fluo-4 were imaged before and after $500 \mu \mathrm{m}$ menthol stimulation, and after $1 \mu \mathrm{m}$ ionomycin treatment. The peak fluorescence intensity was normalized to ionomycin. Gray arrow indicates the cell corresponding to the trace. Roman numerals indicate depicted frames. $\boldsymbol{B}$, Western blot of TRPM8 in untransfected HEK293T cells, untransfected F11 cells, and F11 cells transfected with TRPM8-pcDNA3. Blotting with anti-TRPM8 antibody results in a $130 \mathrm{kDa}$ band in both untransfected and transfected F11cells, indicating endogenous TRPM8 expression on lane 2. HEK293T cells were used as negative control. Cells were lysed and calibrated for equal protein loading using GAPDH (40 kDa band) as protein loading control. C, TIRFM on immunocytochemical representative samples from untransfected F11 cells before and after menthol treatment. Detection with TRPM8 antibody shows a low and discrete expression pattern of particles before menthol treatment. Samples fixed after $30 \mathrm{~s}$. Menthol treatment showed a significant increase in the number of particles. Scale bar, $2 \mu \mathrm{m}$. D, Biotinylation assay on untransfected F11 cells shows an increase in the presence of TRPM8 channels at the PM after menthol treatment. Cells were calibrated for equal protein loading using Transferrin Receptor (TfR; $95 \mathrm{kDa}$ band) as protein loading control. E, TIRFM on membrane sheet preparations before and after menthol treatment. F11 membrane sheets from untransfected cells were formed by a brief ultrasound pulse and directly fixed and stained for TRPM8 detection. Low expression of particles at the PM is observed in basal conditions (left). Samples fixed after $30 \mathrm{~s}$ of menthol treatment show an increase in the particle density at cell surface (right). White line indicates membrane boundaries. Scale bar, $2 \mu \mathrm{m}$.

tions affecting surface expression, seems to be of major physiological relevance (Morenilla-Palao et al., 2009; Pertusa et al., 2012). The consequences of the regulation of the surface expression of TRPM8 channels are underscored by the fact that activation of $\mu$-opioid receptors leads to the internalization of TRPM8 channels, revealing a general mechanism explaining the distorted cold sensitivity upon administration of opioid-derived analgesics (Shapovalov et al., 2013).

Here, we show that the recruitment of TRPM8-containing vesicles is transitory and sensitive to TRPM 8 activation, suggesting a positive feedback of the channel response at the cellular level. Our pharmacological approach in transfected HEK293T cells indicates that the agonist-induced recruitment stimulates the exocytic pathway and partially inhibits the endocytic process, leading to an overall increased cell-surface expression of functional TRPM8 channels. Moreover, electrophysiological recordings from TRPM8-containing cold receptors in skin nerve preparations indicate that proper trafficking is essential to maintain normal cold sensitivity.

\section{Materials and Methods}

Cell culture and expression. F11 cells (provided by Dr. S.E. Gordon) were cultured in F12 Ham's nutri-mix supplied with 20\% FBS (both Invitrogen) and HAT supplement mix (Sigma). HEK293T cells were cultured in DMEM, supplied with $10 \%$ FBS (both Invitrogen). Cells were plated on poly-L-lysine (Sigma-Aldrich) coated coverslips and transfected using lipofectamine (Invitrogen) according to the manufacturer's instructions. All recordings were performed $12-36 \mathrm{~h}$ after transfection. Low transfection was accomplished at 12-18 h; Western blots were performed after $24 \mathrm{~h}$.

cDNA constructs. For heterologous expression in mammalian cells, full-length rat TRPM8 coding sequence (provided by Dr. D Julius, UCSF; GeneBank NM_134317) was cloned in frame into EcoRI and XmaI sites of the mammalian expression vectors pEGFP-N1 (Clontech Laboratories) and pcDNA3 (Invitrogen).

Solutions and reagents. External bath solution contained the following (in mM): $140 \mathrm{NaCl}, 10 \mathrm{HEPES}, 5 \mathrm{KCl}, 2 \mathrm{MgCl}, 2 \mathrm{CaCl}, 10$ glucose (all Sigma-Aldrich), pH7.4; 295 mOsm was used to perform all imaging experiments: menthol $(50-500 \mu \mathrm{M})$, icilin (1 $\mu \mathrm{M})$, methyl- $\beta$ - cyclodextrin $(\mathrm{M} \beta \mathrm{CD}, 10 \mu \mathrm{M})$, cytochalasin $\mathrm{D}(\mathrm{cytoD}, 1 \mu \mathrm{M})$, ionomycin (iono, $1 \mu \mathrm{M}$ ) (all Sigma-Aldrich); and [N-(4-tert-butylphenyl)-4-(3chloropyridin-2-yl)piperazine-1-carboxamide] (BCTC, $1 \mu \mathrm{M}$ ) and thapsigargin $(1 \mu \mathrm{M})$ (both Tocris Bioscience).

Calcium imaging. F11 cells cultured on glass coverslips were incubated for $20 \mathrm{~min}$ with Fluo-4AM calcium indicator ( $1 \mu \mathrm{M}$, Invitrogen) in extracellular buffer containing $5 \mathrm{mM} \mathrm{CaCl}_{2}$. After TRPM8 agonist stimulation (menthol or icilin), ionomycin was added at the end of each experiment. Fluorescence intensities of individual cells were quantified using micro-manager plug-in (Universal Imaging) for ImageJ and Origin 7 (Microcal) Average fluorescence intensities measured in a cytoplasmic ROI $\left(\mathrm{F}_{\text {cell }}\right)$ were quantified and normalized by the maximal fluorescence.

Western blotting and cell surface labeling with biotin. Both F11 and HEK293T cells either untransfected or transfected with $10 \mu$ g of TRPM8pcDNA3 construct were plated in $10 \mathrm{~cm}$ dishes. Cell extracts were fractionated via SDS-PAGE and blotted onto nitrocellulose filters. TRPM8 was detected with a rabbit polyclonal anti-TRPM8 antibody (1:400, Alomone Labs). Biotinylation assays were performed on untransfected F11 cells and HEK293T cells transfected with $10 \mu \mathrm{g}$ of TRPM8-pcDNA3. Cells plated on $10 \mathrm{~cm}$ dishes coated with poly-L-lysine (Sigma) were washed 3 times with ice-cold PBS solution and treated for 30-60 s with mock or $500 \mu \mathrm{M}$ menthol solutions. Immediately, cells were incubated with the NHS-LC-LC-biotin (Pierce) in biotinylation buffer ( $2 \mathrm{~mm}$ $\mathrm{CaCl}_{2}, 150 \mathrm{~mm} \mathrm{NaCl}$, and $10 \mathrm{~mm}$ triethanolamine) for $30 \mathrm{~min}$ at $4^{\circ} \mathrm{C}$. The biotinylation reaction was stopped with washes of PBS containing 100 mM glycine and additional washes with PBS. Cells were lysed with RIPA buffer (50 nм Tris-HCl, pH 7.4, 150 mm NaCl, 1\% Nonidet P-40, 0.5\% sodium deoxycholate, $0.1 \%$ SDS, $1 \mu \mathrm{g} / \mathrm{ml}$ leupeptin, $5 \mu \mathrm{g} / \mathrm{ml}$ soybean trypsin inhibitor, $0.1 \mu \mathrm{g} / \mathrm{ml} \mathrm{PMSF}$, and $10 \mathrm{~mm} \mathrm{~N}$-methylmaleimide). Cell extracts were centrifuged at $16,000 \times \mathrm{g}$ for $1 \mathrm{~h}$. Supernatants were incubated with $50 \mu \mathrm{l}$ of neutravidine-agarose. The precipitates were collected by centrifugation, washed with 100 and $300 \mathrm{~mm} \mathrm{NaCl}$, resuspended in buffer, and subjected to Western blotting.

Immunocytochemistry. Cells were fixed after mock or menthol treatment with $4 \%$ PFA for 15 min and subsequently permeabilized with $0.2 \%$ Triton X-100, blocked with $2 \%$ BSA, and incubated with a primary antibody (rabbit polyclonal anti-TRPM8 antibody; 1:400, Phoenix Pharmaceuticals) overnight at $4^{\circ} \mathrm{C}$. Cells were subsequently washed and incubated with a fluorescent secondary anti-rabbit antibody 
A
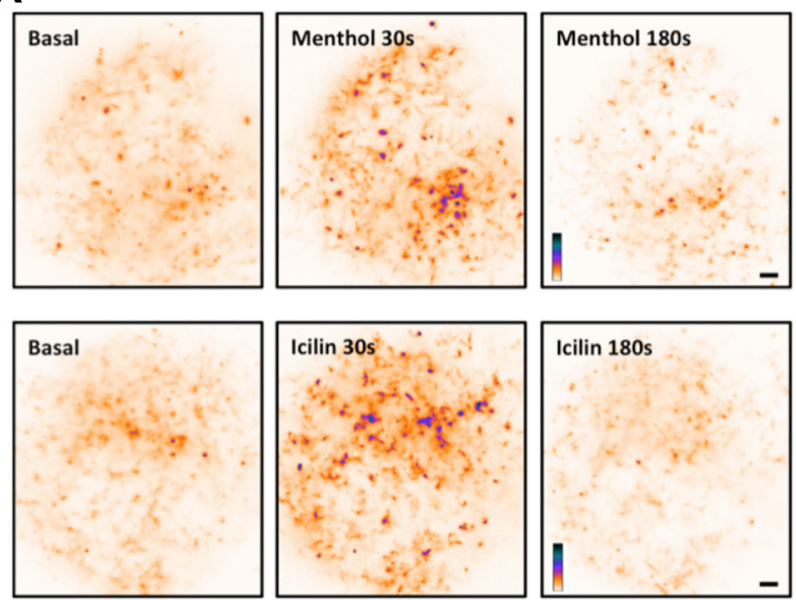

\section{E}
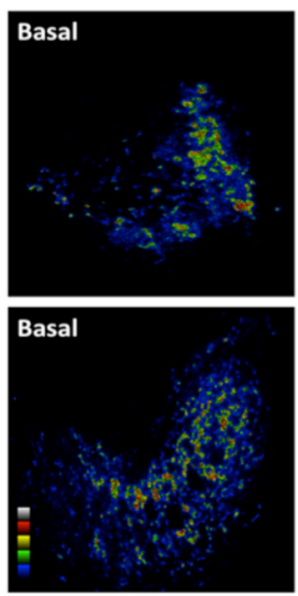

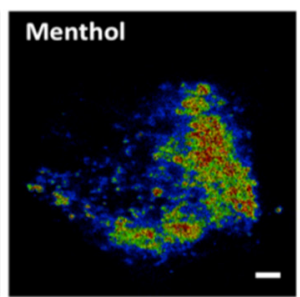

Icilin

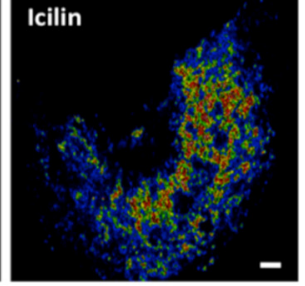

B

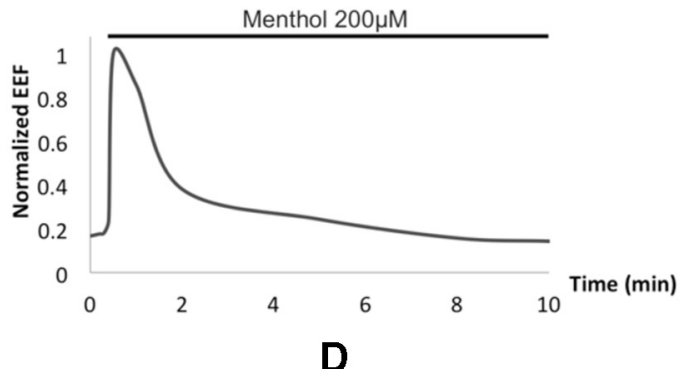

C
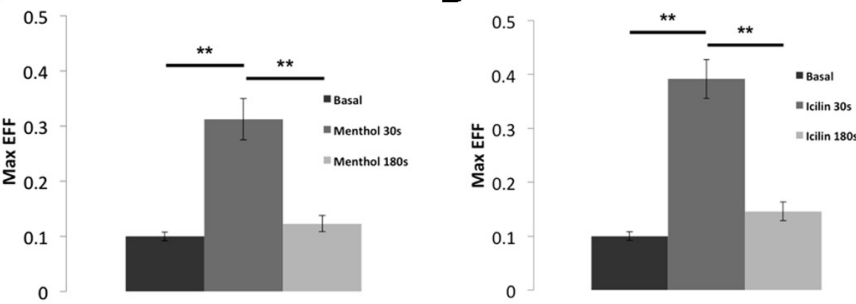

$\mathbf{F}$

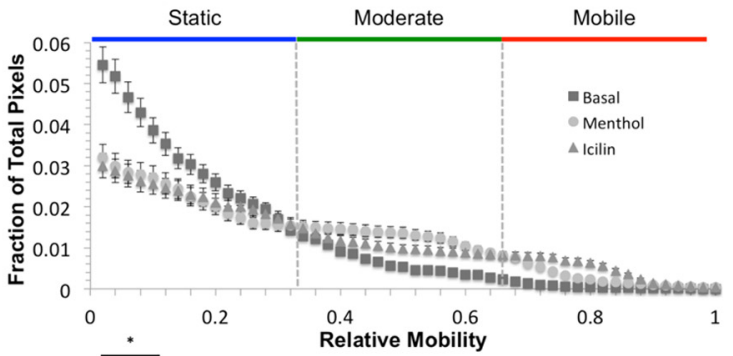

$\mathbf{G}$

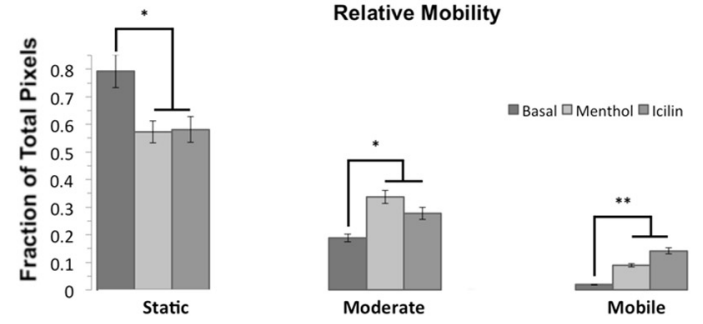

Figure 2. Menthol and icilin increase near-PM TRPM8-EGFP (enhanced green fluorescent protein) localization in transfected F11 cells. $A$, Images representing the overall presence of the channel after 200 frames (addition of all frames) basally and after menthol or icilin treatment. Purple shaded regions represent higher intensity, suggesting a transient increase in TRPM8-containing vesicle residency at PM after agonist treatment. $\boldsymbol{B}$, Time course of the fluorescence signal at the EFF showing that acute menthol treatments evoke a transitory response. $\boldsymbol{C}, \boldsymbol{D}$, EFF increased significantly in response to TRPM8 agonists. There is a threefold and fourfold increase of fluorescence detection in the presence of menthol and icilin, respectively. $\boldsymbol{E}$, The mobility of TRPM8-EGFP-containing vesicles is increased after agonist treatment. Color-coded mobility images reflect variation of a position within a $30 \mathrm{~s}$ recording after stimulus. Red shades represent most mobile regions. Blue shades represent less mobile zones. $\boldsymbol{F}$, Distribution histogram showing the fraction of pixels with the specified mobility. An increase in the relative mobility of TRPM8-containing vesicles is shown after brief agonist treatment. Color bars on top define the regions integrated. G, Population statistics of the integrated relative pixel mobility of TRPM8-EGFP-containing vesicles. Pixels were separated into three groups: static, moderately mobile, and highly mobile. Data are mean \pm SEM. ${ }^{*} p<0.05 .{ }^{* *} p<0.01$. Scale bars, $1 \mu \mathrm{m}$.

(AlexaFluor-488, Invitrogen) for $1 \mathrm{~h}$ at room temperature $\left(20^{\circ} \mathrm{C}\right)$. Immunofluorescence was detected using an Olympus microscope.

Membrane sheet preparation. Untransfected F11 cells were washed twice in ice-cold imaging buffer (HBS, pH 7.4), before being subjected to 3 sonication pulses of $40 \%$ power, 1 s each (Cole Palmer 4710 Ultrasonics Homogenizer) directly on coverslips. Cells were washed twice in Ringer's solution before mock and menthol treatment for $30 \mathrm{~s}$ and then continued with fixation and immunocytochemical analysis steps previously described.

Total internal reflection fluorescence (TIRF) microscopy. F11 and HEK293T cells were imaged using a through-the-objective TIRF microscope. A thin evanescence field ( $170 \mathrm{~nm}$ next to the glass-water interface) was generated using 473 or $532 \mathrm{~nm}$ diode pump lasers (LaserGlow). Both lasers were focused onto a $10 \mu \mathrm{m}$ optical fiber and transmitted via the rear illumination port of an Olympus IX71 microscope. Digitally synchronized shutters (Vincent Associates) controlled exposure times through a high-numerical aperture objective $(60 \times, 1.49 \mathrm{NA}$, oil; Olympus). Fluorescence emission was recorded by a 12ER cooled-CCD camera (Hamamatsu Photonics). Imaging was performed at $10 \mathrm{~Hz}$ using micro-manager plug-in (Universal Imaging) for ImageJ.
Live cell imaging and analysis of diffusion. For visualizing the effect of TRPM8 activation, F11 cells were seeded on $25 \mathrm{~mm}$ glass coverslips (VWR) and TRPM8-EGFP was transiently expressed 12-18 h after transfection; the cells were imaged at room temperature. Menthol (500-200 $\mu \mathrm{M})$ or icilin $(1 \mu \mathrm{M})$ was used in experiments to activate TRPM8. For experiments aiming to block TRPM8 activity, BCTC $(10 \mu \mathrm{M})$ was added. Particle tracking, population, and trajectory analyses were performed using custom-made software (Veliz et al., 2010).

Image analysis. Image sequences of $30 \mathrm{~s}$ length were analyzed with ImageJ (National Institutes of Health). The background fluorescence was subtracted, and fusion events were identified as changes in intensity and counted. The number of events was normalized to cell area. Then, the number of fusions per pixel $^{2}$ was normalized by the averaged activity of vector transfected cells. To calculate fluorescence kinetics, ROIs were established on previously identified fusion spots, and the fluorescence time course of fusion events was recorded. A single exponential decay function was fitted to the fluorescence relaxation process, and time constants $(\tau)$ were calculated. To determine the diffusion constant, we tracked single fluorescent particles (nonfused vesicles) and calculated 
A

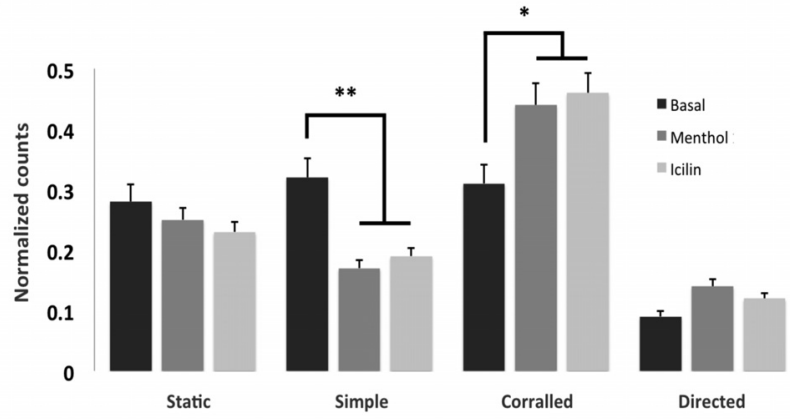

B

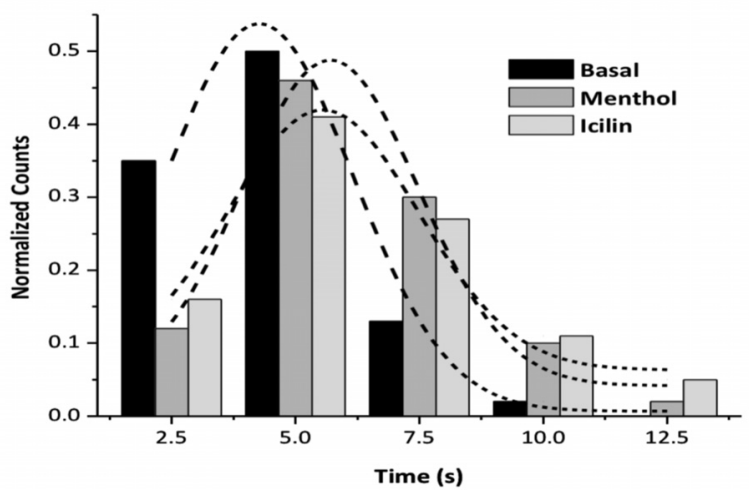

Figure 3. Differences in subgroups of particles are observed by TIRFM before and after agonist treatment. $A$, Differences in particle diffusion modes in response to agonists. Different diffusion modes are noted in percentage units. Strict Brownian diffusion and anomalous diffusion were gathered in one single group (simple diffusion). $\boldsymbol{B}$, Corralled particle lifetime after stimulation. TRPM8-containing vesicles augment their corralled lifetime near PM regions after menthol or icilin treatment. Data are mean \pm SEM. ${ }^{*} p<0.05 .{ }^{* *} p<0.01$.

the mean square displacement (Qian et al., 1991) and the diffusion coefficient.

To quantify vesicle mobility, we consider only the likelihood that a particle moved. The fluorescence signal was filtered to select nearmembrane vesicles. The low threshold was set at 2 SDs above the mean of the camera and photon noise. According to the threshold, images were converted to binary. For each pixel of the image sequence, the mobility function $(\delta)$ was calculated using the following equation:

$$
\delta=\frac{\sum_{1}^{n-1}\left(f_{i}-f_{(i+1)}\right)^{2}}{n}
$$

where $f$ is the amplitude value of each pixel ( 1 or 0$)$ in the binary image, " $i$ " is a frame number, and " $n$ " corresponds to the total number of frames. The processed image reflects object mobility pixel by pixel ("mobility image") where each pixel represents a color-coded $\delta$ value. In mobility distribution histograms, $\delta$ values are presented as a fraction of the theoretical maximum (1). These values were obtained for each cell, normalized, averaged, and presented in probability distribution plots (number of pixels per total pixels).

Variance analysis. Nonstationary noise analysis was used to estimate the maximum probability of opening and single-channel conductance. We collected 120 current records during activation of the channels by a $100 \mathrm{~ms}$ depolarization voltage step from 0 to $160 \mathrm{mV}$. Ensemble averaged current, $\langle I\rangle$, and its variance, $\sigma^{2}$, on each isochrone were computed. The variance as a function of $<I>$ data was fitted by the equation, $\sigma^{2}=$ $i<I>-\left(\langle I\rangle^{2} / N\right)$, where ' $i$ ' is the single-channel unitary current and $N$ is the number of channels in the patch. The maximum open probability, $P_{\mathrm{o}(\max )}$, was obtained according to the relation, $P_{\mathrm{o}(\max )}=I_{\max } /(i N)$, where $I_{\max }$ is the maximum mean current measured in the experiment.
For noise analysis, data were acquired at $20 \mathrm{kHz}$ and filtered at $10 \mathrm{kHz}$. Data acquisition was made using an Axopatch 200B (Molecular Devices).

Single-fiber recordings. The isolated skin-saphenous nerve preparation and single-fiber recording technique were used (Zimmermann et al., 2009). Skin preparations were from C57BL/6 mice and TRPM8-deficient mice (from A. Patapoutian; backcrossed for at least five generations on C57BL/6 background). The skin was kept under laminar superfusion of carbogen gassed synthetic interstitial fluid; and in an adjacent recording chamber, the saphenous nerve was overlaid with paraffin oil and split into thin filaments. Filament by filament, receptive fields of single mechano-cold-sensitive $\mathrm{C}$ fibers (CMC fibers) or monomodal coldsensitive fibers (CC fibers) were searched for with blunt glass rods or ice cubes, respectively (Zimmermann et al., 2009, 2011). The CMC fibers were further characterized with a set of gravity-driven von Frey filaments and with a standardized $60 \mathrm{~s}$ cold stimulus. For application of menthol and thermal stimuli, the receptive fields were isolated from the surrounding fluid with a Teflon ring (volume 300-400 $\mu$ l) and kept continuously perfused with synthetic interstitial fluid or menthol 50 or $500 \mu \mathrm{M}$ at a rate of $10 \mathrm{ml} / \mathrm{min}$ at $30^{\circ} \mathrm{C}$. To apply cold stimuli, we used a custom-designed countercurrent temperature exchange application system (Zimmermann et al., 2009). The criterion for assigning cold responsiveness to a fiber was a discharge of at least 3 spikes, whereby the cold threshold was considered as the first spike discharged during cooling. Responsiveness to menthol was assigned to a fiber when the fibers increased the magnitude of the cold response or developed a cold response upon menthol treatment. This increase was registered as number of spikes of the cold response (increase by 1.5 -fold).

Botulinum neurotoxin Type A (BoNTA) was used to test the effect of lack of vesicle fusion on cold and menthol-sensitized cold responses of CMC and CC fibers. BoNTA was purchased in batches of $50 \mathrm{U}$ from Allergan and dissolved in Ringer's solution in aliquots of 1-2 $U$ and kept at $-80^{\circ} \mathrm{C}$. Before the experiment, skin preparations were kept refrigerated in a glass beaker with $3 \mathrm{ml}$ synthetic interstitial fluid containing at least 2.5 up to $8 \mathrm{U}$ of BoNTA for 2.5-8 h (depending on whether the first or second preparation was used). BoNTA was dissolved fresh every $10 \mathrm{~d}$ because its potency is constantly reduced when kept dissolved (loss of up to $70 \%$ within $14 \mathrm{~d}$ at $-20^{\circ} \mathrm{C}$ are reported). To estimate cold responses of CC fibers in absence of TRPM8, we used skin-nerve preparations from male TRPM8 ${ }^{-1-}(n=9)$ mice and age-matched littermates $(n=9)$. Receptive fields of cold-sensitive $C$ fibers were identified by probing with pieces of ice cubes and then tested for mechanical sensitivity using glass rods.

Data analysis. Unless stated, group data are presented as mean \pm SEM. Statistical comparisons were made using one-way ANOVA and Bonferroni mean test. For statistical analysis of single fiber recordings, the Wilcoxon matched-pairs test was calculated, and differences were considered significant at $p<0.05$ (Statistica version 6; StatSoft). A value of $p=0.05$ was considered statistically significant.

\section{Results}

\section{F11 cells natively express TRPM8 channels}

It has been demonstrated that F11 dorsal root ganglion hybridoma cells express TRPV channels endogenously (Bender et al., 2005). We therefore tested whether these cells also natively express TRPM8 channels. Calcium imaging experiments indicate that $\sim 10 \%$ of the cell population respond to the TRPM 8 agonist menthol $(500 \mu \mathrm{M} ; n=12$; Fig. $1 A)$. We confirmed the endogenous expression of TRPM8 by Western blot analysis (Fig. $1 B$ ) and by TIRF imaging immunocytochemical staining of untransfected F11 cells (Fig. 1C). We observed a discrete expression pattern at the PM in basal conditions and an increase in the number of immunoreactive puncta after $30 \mathrm{~s}$ of menthol treatment (Fig. 1C; $200 \mu \mathrm{M} ; n=12$ ). Interestingly, a similar result was observed through biotinylation assays on F11 cells, where $30 \mathrm{~s}$ to $1 \mathrm{~min}$ of menthol incubation was enough to increase the number of channels at the PM (Fig. 1D). Then, F11 cells were subjected to an ultrasound pulse "unroofing" them and leaving an intact sheet of 
Table 1. Diffusion constants of TRPM8-EGFP-containing particles change in response to agonists either in HEK293T or F11 cells

\begin{tabular}{|c|c|c|c|c|c|c|}
\hline \multirow[b]{2}{*}{ Diffusion modes } & \multicolumn{3}{|c|}{ Diffusion coefficients on F11 } & \multicolumn{3}{|c|}{ Diffusion coefficients on HEK293 } \\
\hline & Basal & Menthol & Icilin & Basal & Menthol & Icilin \\
\hline Directed & $10.72 \times 10^{-2}$ & $26.67 \times 10^{-2}$ & $22.16 \times 10^{-2}$ & $11.24 \times 10^{-2}$ & $29.83 \times 10^{-2}$ & $23.65 \times 10^{-2}$ \\
\hline Simple & $7.98 \times 10^{-2}$ & $8.17 \times 10^{-2}$ & $6.59 \times 10^{-2}$ & $8.61 \times 10^{-2}$ & $9.04 \times 10^{-2}$ & $7.52 \times 10^{-2}$ \\
\hline Corralled & $1.83 \times 10^{-2}$ & $0.97 \times 10^{-2}$ & $1.08 \times 10^{-2}$ & $1.72 \times 10^{-2}$ & $1.04 \times 10^{-2}$ & $0.92 \times 10^{-2}$ \\
\hline
\end{tabular}

A

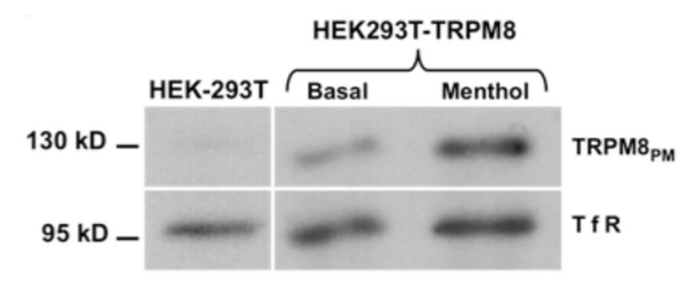

C

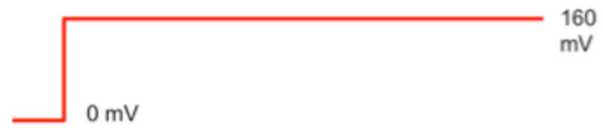

D
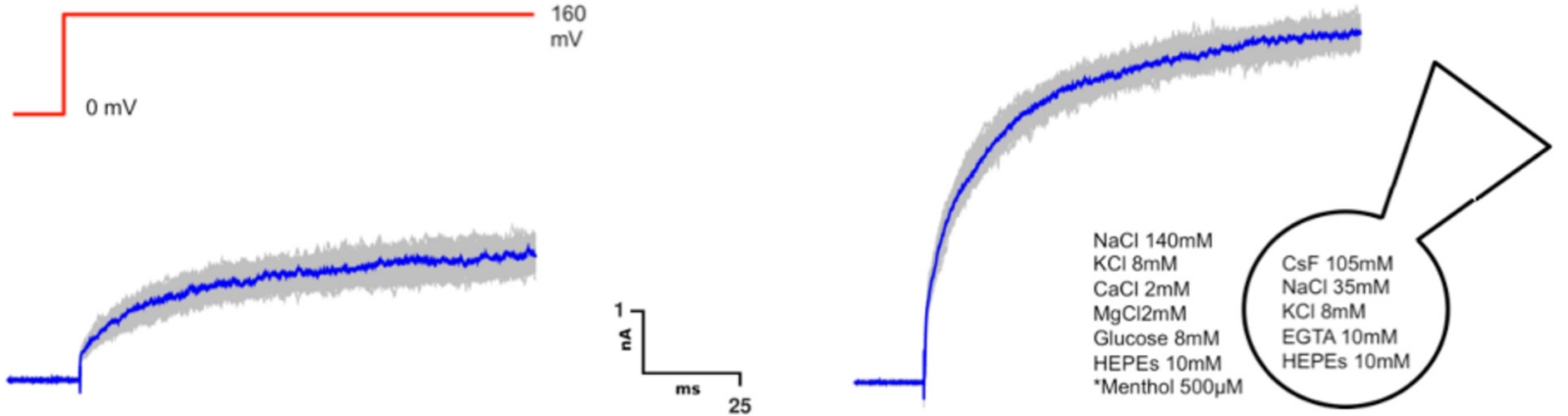
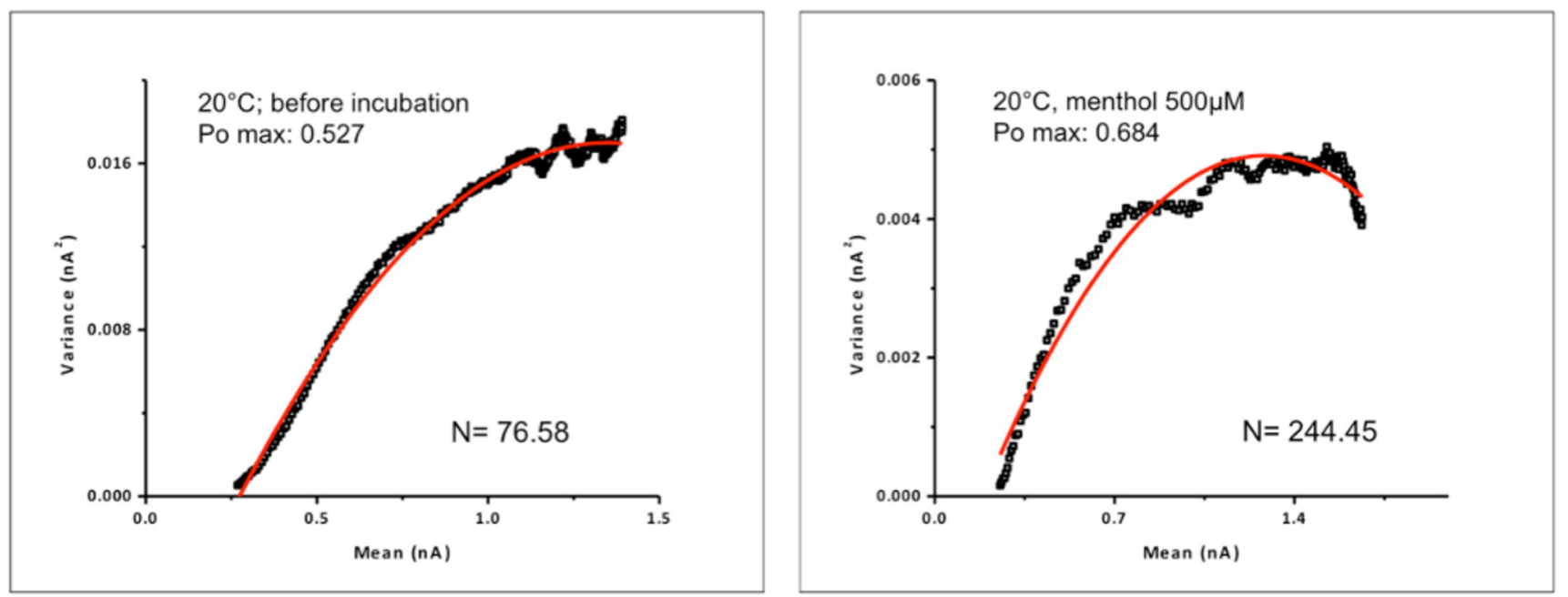

Figure 4. TRPM8 channels recruited to the PM are functional. A, Biotinylation assay on HEK293T cells transfected with TRPM8-pcDNA3 showing a change in the amount of receptor at the cell surface after $1 \mathrm{~min} 500 \mu \mathrm{m}$ menthol incubation. Cells were calibrated for equal protein loading using TfR ( $95 \mathrm{kDa}$ band) as protein loading control. $\boldsymbol{B}$, Quantification of the Western blot in $\boldsymbol{A}$ shows an evident increase in the presence of TRPM8 channels at the PM after menthol treatment. C, Representative set of current traces (120) recorded in HEK293T cells expressing TRPM8 channels for control (left) and menthol-treated (right) cells. Untreated cells and vehicle-incubated cells showed as control ( $0.05 \%$ ethanol) present no differences. Cells were recorded on whole-cell mode and pulsed 120 times from 0 to $160 \mathrm{mV}$ every $1 \mathrm{~s}$. Blue traces represent mean current. $\boldsymbol{D}$, Variance analysis of cellular response. Variance was plotted against the mean current and fitted to a parabola function of the form $\mathrm{I}_{\text {total }}=\mathrm{iNP}_{0}$, where " $I$ " corresponds to the unitary current, " $N$ " to the number of channels, and $P_{0}$ to the open probability. There is an increase in the average current after 2 min of menthol treatment $(500 \mu \mathrm{M})$. This increase is explained by a near threefold increment in the number of active channels at the PM and a $15 \%$ increase in the $P_{0}$, and assumes no significant change in the single-channel conductance. $n=6$. 
Table 2. Summary of the number of channels $(N)$, open probability $\left(P_{0}\right)$, and singlechannel conductance $(I)$ values before and after menthol incubation

\begin{tabular}{lcc}
\hline & Vehicle & Menthol $500 \mu \mathrm{M}$ \\
\hline$N$ & $108.72 \pm 44.8$ & $334.84 \pm 101.2$ \\
$P_{0}$ & $0.48 \pm 0.11$ & $0.65 \pm 0.06$ \\
$I$ (pS) & $76.98 \pm 8.2$ & $72.59 \pm 8.7$ \\
\hline
\end{tabular}

native membrane attached to the coverslip (Bar-On et al., 2008). TIRF imaging of membrane sheet samples showed a similar increment of immunoreactivity after $30 \mathrm{~s}$ of menthol treatment of the intact cell before unroofing (Fig. 1E), suggesting an intimate and stable contact of channel-containing vesicles with the PM.

The distribution and dynamics of TRPM8-containing vesicles varies upon agonist treatment

Results from our previous work (Veliz et al., 2010), and the menthol-induced effect on the channel density at the PM (Fig. $1 C-E$ ), led us to explore the dynamic behavior of TRPM8containing vesicles after agonist and antagonist stimulation. To determine whether the mobility and near-membrane diffusion of TRPM8-containing vesicles changes after stimulation, we used TIRF imaging to visualize F11 cells transfected with TRPM8EGFP. Well-defined puncta were observed at the evanescent field with a high signal/noise ratio allowing us to track single vesicles. The moving spots were coherent, as they were never observed to split or merge into smaller or larger bodies.

We compared the overall presence of TRPM8-EGFP at nearmembrane regions before and after exposure to menthol or icilin. Again, $30 \mathrm{~s}$ to $1 \mathrm{~min}$ treatments were enough to produce an increase in the density of channels within the evanescent field, resembling the native behavior of the receptor observed in untransfected F11 cells (Fig. 2A). Notably, the effect of menthol on vesicle recruitment was transitory and regularly washed out after 6-7 min (Fig. 2A,B). To quantify the level of agonist-induced recruitment we integrate the evanescence field fluorescence (EFF) per unit of area, before and after treatments. The results show a significant increase in the number of channels per area after agonist treatment (Fig. 2C,D). Menthol induced an approximately threefold increase (200 $\mu \mathrm{M} n=30 ; p<0.01)$, whereas icilin induced a nearly fourfold increase ( $1 \mu \mathrm{M} ; n=30 ; p<0.01)$. We also performed a pixel-by-pixel mobility analysis (Brauchi et al., 2008) over 200 sequential images obtained at $10 \mathrm{~Hz}$ (Fig. 2E). The analysis indicates an increase in the relative mobility of TRPM8-containing vesicles within the evanescent field after a brief incubation with menthol or icilin (Fig. 2E-G). So far, our data suggest that TRPM8 agonists influence vesicular trafficking of the channel.

To examine the dynamics of individual TRPM8-containing vesicles in transfected F11 cells, we performed single particle tracking on TIRF mode, followed by a thorough diffusional analysis (Veliz et al., 2010). We were able to classify the trajectories into different diffusion modes and to extract the averaged diffusion coefficient (D) for each population. A total of 180 trajectories were analyzed (Fig. 3; Table 1). As shown in Figure 3A, the percentage of vesicles with simple diffusion decreased compared with the control population by $47 \%$ after menthol $(200 \mu \mathrm{M} ; n=$ $25 ; p<0.01)$ and $40 \%$ after icilin treatment $(1 \mu \mathrm{M} ; n=25 ; p<$ $0.05)$. In contrast, the number of vesicles arrested in corralled areas increased significantly by $38 \%$ and $49 \%$ (menthol, $n=25$; $p<0.05$; icilin $n=25$; $p<0.05$ ). However, no significant differences were found in particles classified as static or undergoing directed motion (Fig. 3A). To define whether individual particles change their diffusion after agonist treatment, we calculated their diffusion coefficient (see Materials and Methods). For particles classified as being in directed or corralled mode motion, incubations with agonists induced a substantial change in their diffusion coefficients ( $n=25, p<0.05$; Table 1$)$. Interestingly, a similar response was observed when the experiment was performed on transfected HEK293T cells (Table 1). The single spots in corralled motion are assumed to be vesicles transporting a discrete number of TRPM8 channels, as demonstrated previously by singlemolecule fluorescence quenching experiments (Veliz et al.,
A
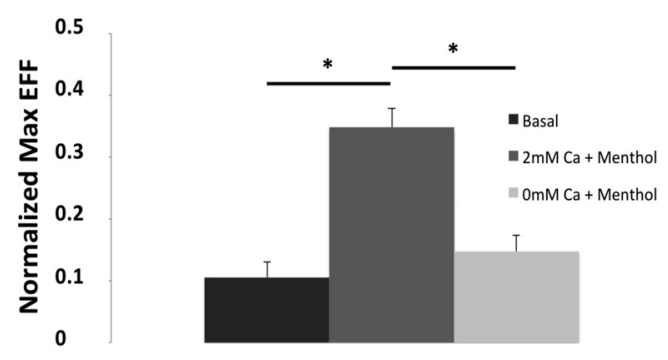

C

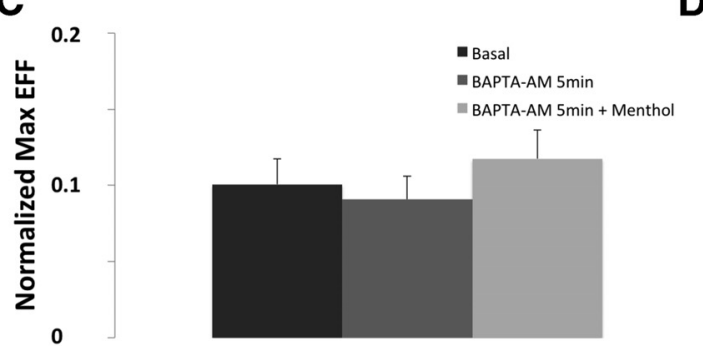

B

D
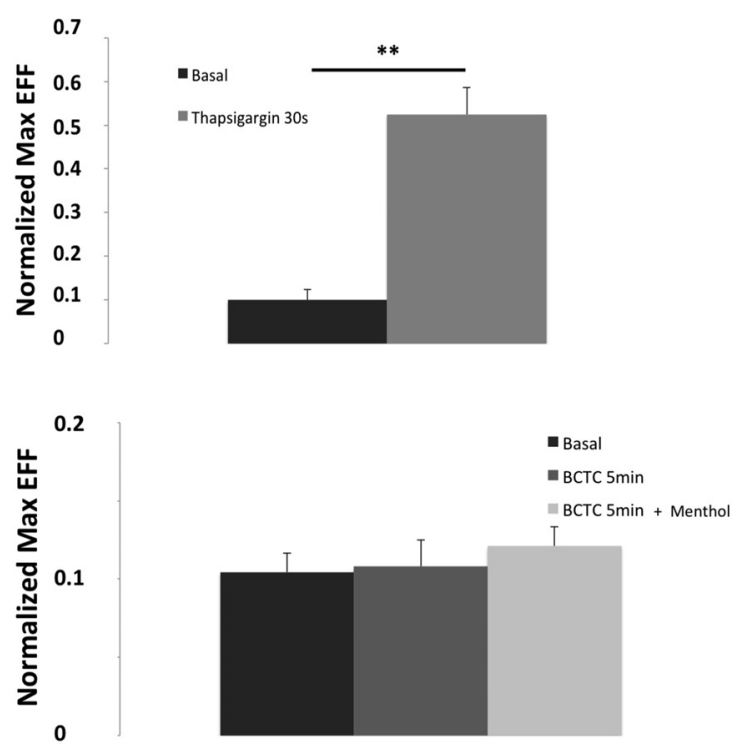

Figure 5. Translocation of vesicles containing TRPM8 are modulated by calcium and channel activity. $\boldsymbol{A}$, Absence of external calcium does not appear to affect normal particle arrival to PM. After stimulation there is not a significant increase of particles near PM, calculated as EFF. $\boldsymbol{B}$, Increase of internal calcium levels after thapsigargin exposure increases the number of TRPM8-containing vesicles. $\boldsymbol{C}$, Treatment with intracellular calcium chelator BAPTA-AM abolishes the menthol stimulated recruitment of vesicles. $\boldsymbol{D}$, Incubations with the selective blocker BCTC are enough to eliminate the effect of menthol on vesicle recruitment. Data are mean \pm SEM. ${ }^{*} p<0.05 .{ }^{* *} p<0.01$. 
A
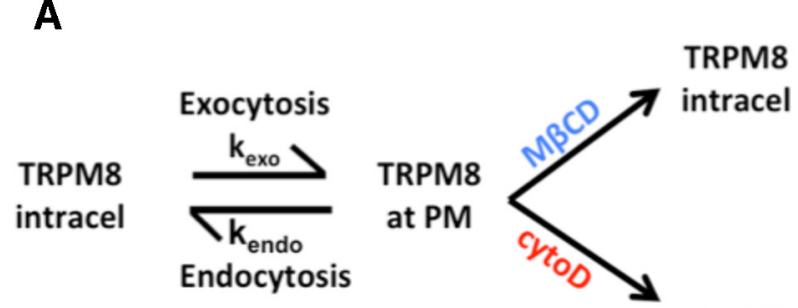

TRPM8 intracel

B
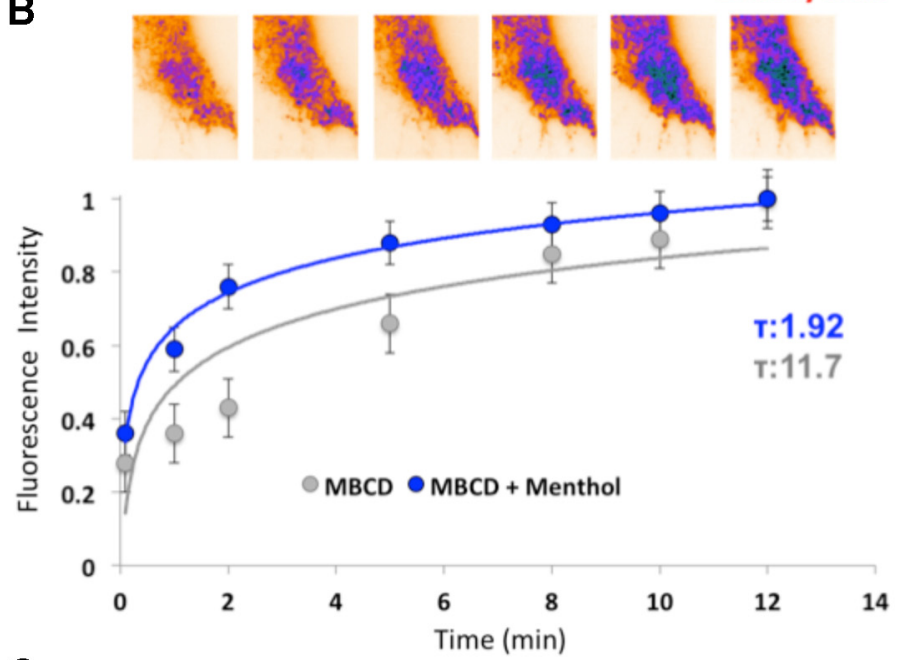

C
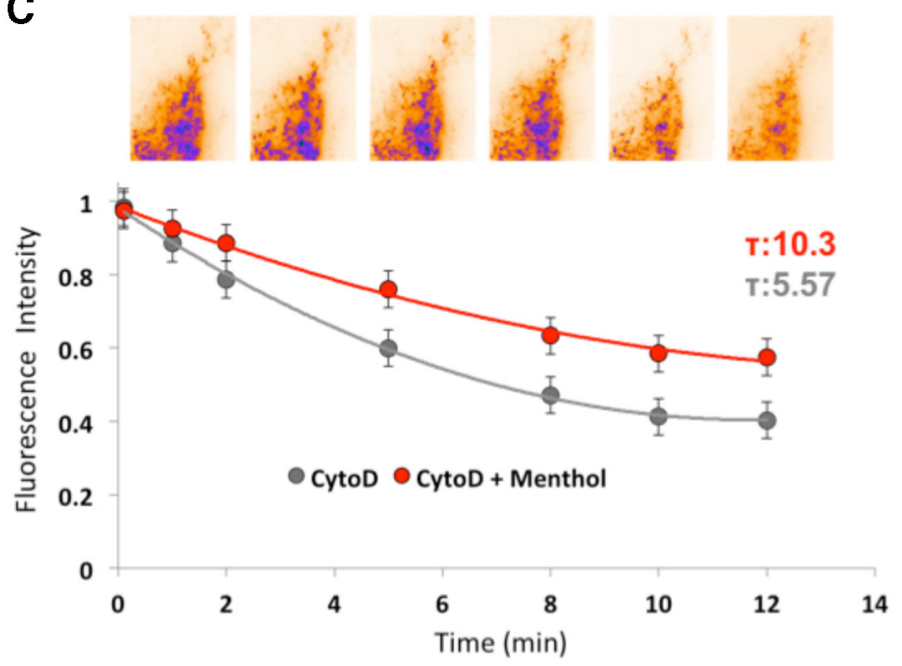

Figure 6. TRPM8 internalization and recruitment are affected after menthol. $\boldsymbol{A}$, Distribution of particles follow a two-state model, where equilibrium constant values during exocytic and endocytic processes vary in the presence of menthol. $\boldsymbol{B}$, Partial inhibition of endocytosis processes after $M \beta C D$ incubation. Decay constant values $(\tau)$ indicate that menthol stimulates $M \beta C D$ dependent exocytosis by $\sim 6$ times (blue circles) in comparison with control conditions (gray circles). Purple shaded regions on the TIRF images represent higher intensity, suggesting an increase in TRPM8-containing vesicles at PM. C, Partial inhibition of exocytosis processes induced by cytoD incubation. Top, Images represent overall presence of particles after cytoD incubation. Purple shaded regions represent higher intensity, suggesting a decrease in the exocytic rate. Comparison of decay constant values $(\tau)$ shows that menthol has a near twofold effect on cytoD-dependent vesicle endocytosis. $n=6$.

2010). In agreement with the increase in the number of particles in corralled motion and the change in the diffusion coefficient, we saw marked differences in the time the corralled vesicles spend proximal to the PM region (Fig. 3B). Overall, results from imaging experiments strongly suggest that TRPM 8 channels that are being transported by a subgroup of vesicles remain dwelling at the PM for longer periods after exposing the cells to either menthol or icilin.

\section{Functional recruitment of TRPM8 channels to the PM}

To confirm that the amount of TRPM8 protein is increased at the PM; and considering that the effect on diffusion was observed in HEK293T cells, we first performed a biotinylation assay followed by Western blot experiments in these cells. An acute exposure of $1 \mathrm{~min}$ to an agonist induced a visible change in the amount of receptor at the membrane (Fig. $4 A, B$ ). To test whether this increase corresponds to an augmentation of the number of functional channels, we performed a nonstationary noise analysis (Alvarez, Gonzalez and Latorre, 2002). This method analyzes the variance of the current trace with respect to the mean current of the voltageinduced response, allowing derivation of the open probability $\left(P_{\mathrm{o}}\right)$, the number of active channels in the patch $(N)$, and the unitary conductance $(I)$ from the same recording. Whole-cell currents elicited by depolarizing steps to $160 \mathrm{mV}$ were recorded from TRPM8-transfected HEK293T cells (Brauchi et al., 2004; Veliz et al., 2010). Two minute treatments of $500 \mu \mathrm{M}$ menthol caused a substantial increase in $P_{\mathrm{o}}$ from the expected $50 \%$ induced by room temperature (Brauchi et al., 2004) to $\sim 65 \%$ (Fig. $4 C, D$ ). Interestingly, this is accompanied with a threefold increase in the number of channels $(n=6 ; p<0.01)$, without affecting single-channel conductance (Fig. $4 D$; Table 2). It is worth noticing that the noise analysis has to be performed under conditions allowing $P_{\mathrm{o}}$ $\sim 50 \%$, to ensure a good fit to a symmetrical rectangular parabola function (Alvarez et al., 2002). For this reason, we performed the experiments at submaximal activation temperature (room temperature $20^{\circ} \mathrm{C}$ ) and saturating agonist concentrations (500 $\mu \mathrm{M}$ menthol).

\section{Menthol-induced recruitment of vesicles depends on TRPM8 conductance}

Calcium ions are key to cell function, including the control of vesicular fusion (Sudhof, 2004; Clapham, 2007). TRPM8 is a calcium-permeable channel, and its activity is in part controlled by a welldocumented calcium-dependent desensitization (McKemy et al., 2002; Reid et al., 2002; Latorre et al., 2011). Thus, we examine the contribution of calcium to the mobilization and arrival of TRPM8-containing vesicles to the PM. We first studied the effect of external calcium by comparing EFF on control and menthol-treated cells, in the presence or absence of $\mathrm{Ca}^{2+}$ in the external medium (Fig. 5). Although extracellular solution containing calcium $(2 \mathrm{mM})$ was 
enough to support normal particle arrival, once calcium was removed there was no considerable increase in the number of vesicles at the membrane after menthol treatment, underscoring the role of external calcium and somewhat ruling out the contribution of intracellular TRPM8 channels (Fig. 5A). Moreover, depletion of intracellular calcium stores with thapsigargin $(1 \mu \mathrm{M})$ significantly increased the number of particles at the membrane within seconds (Fig. $5 B ; n=12 ; p<0.01$ ), indicating that an increase on the intracellular calcium concentration is critical for the fast recruitment of TRPM8 to the PM. In support of this, intracellular calcium chelation with $20 \mu \mathrm{M}$ BAPTA-AM inhibited this agonist-induced recruitment of the channel (Fig. 5C).

There is always a fraction $(\sim 30 \%)$ of TRPM8 channels that are immobile at the membrane (Veliz et al., 2010) (Fig. 3A). To test whether calcium influx through active TRPM8 channels located at the PM was enough to induce this recruitment, we used the TRPM8 blocker BCTC (Valenzano et al., 2003). One minute incubation with BCTC $(10 \mu \mathrm{M})$ was enough to occlude the effect of menthol $(200 \mu \mathrm{M})$ on vesicle recruitment (Fig. 5D). Thus, the results suggest that translocation of vesicles containing TRPM8 channels are modulated by an increase on the intracellular calcium and that TRPM8 activity at the $\mathrm{PM}$ is sufficient to support this modulation.

\section{Endocytotic and exocytotic mechanisms are differentially affected by menthol}

We next asked whether a change in the ratio between endocytosis and exocytosis underlies the agonist-induced TRPM8 modulation. Vesicle recycling can be understood as a process of distribution of particles in two different and discrete energy levels (i.e., intracellular or inserted at PM) and therefore can be described considering a two-state model where the rate constants $\mathrm{k}_{1}$ and $\mathrm{k}_{-1}$ correspond to exocytosis $\left(\mathrm{k}_{(\mathrm{exo})}\right)$ and endocytosis $\left(\mathrm{k}_{(\mathrm{endo})}\right)$, respectively (Fig. $6 A$ ), and the overall reaction constant $\mathrm{Keq}_{(\mathrm{exo})}=$ $\mathrm{k}_{\text {(endo) }} / \mathrm{k}_{(\text {exo) }}$. Once menthol is added to TRPM8-transfected cells, a new $\mathrm{Keq}_{\text {(exo) }}$ ' is set, describing the increase in channel density at the PM. We reasoned that comparing the effect of menthol while preferentially inhibiting exocytic or endocytic pathways will allow for the calculation of the new $\mathrm{Keq}_{(\mathrm{exo})}$ ' directly from the reaction rates (i.e., $\mathrm{k}_{\mathrm{endo}}, \mathrm{k}_{\text {exo }}$; Fig. $6 A$ ). To do this, we create two different scenarios: on one hand, we incubate the cells with $\mathrm{M} \beta \mathrm{CD}$ to inhibit endocytosis. On the other hand, to induce the opposite scenario, we used cytoD. Then, we addressed the contribution of the independent processes to the overall equilibrium by comparing the time constant $(\tau)$ of the fluorescence signal from TRPM8-GFP-transfected cells incubated with either $\mathrm{M} \beta \mathrm{CD}$ or cytoD, in the presence or absence of menthol. In a previous work, we demonstrate that $\mathrm{M} \beta \mathrm{CD}$, a cholesteroldepleting agent, causes a large accumulation of TRPM8 at the PM (Veliz et al., 2010), therefore making $\mathrm{k}_{\text {endo }}$ small versus $\mathrm{k}_{\text {exo }}$. We then compared the time constants of $\mathrm{M} \beta \mathrm{CD}$-induced fluorescence accumulation for Ringer's solution alone and mentholincubated cells. We observed a sixfold acceleration of $\mathrm{k}_{\text {exo }}(11.7 \mathrm{~s}$ vs 1.9 s) after menthol incubation (Fig. 6B). CytoD disrupts the actin cytoskeleton (Flanagan and Lin, 1980; Valentijn et al., 1999), thereby interfering with vesicular transportation, slowing down exocytosis. It is worth noting that, although it is known that cytoD inhibits actin polymerization impairing exocytosis, it also affects clathrin-independent endocytosis to some extent (Tilney et al., 1990; Torgersen et al., 2001). Regardless of the possible effect over the endocytic process, we observed an evident decay in the total fluorescence after incubations with cytoD ( $5 \mu \mathrm{M}$; Fig. $6 C)$, indicating that the exocytic rate $\left(\mathrm{k}_{\text {exo }}\right)$ became substantially smaller than the endocytic $\left(\mathrm{k}_{\text {endo }}\right)$. Under these conditions, menthol induced a twofold difference in $\mathrm{k}_{\text {endo }}$, suggesting a partial inhibition of endocytosis after menthol treatment. Our results suggest that, although menthol stimulation affects both endocytic and exocytic machinery, the effect over vesicle recruitment to the PM was somewhat stronger. According to our previous results (Fig. 5), the effect on the exocytic pathway may be linked with changes in the local calcium concentration. On the other hand, changes in endocytosis may be associated with the stabilization of the fused vesicle by a mechanism still unknown. In summary, from the menthol-induced alteration of the rates, we can calculate a threefold increase in the equilibrium constant, ultimately reflected as an increase in the number of channels present at the PM.

\section{BoNTA reduces the cold-sensitizing effect of menthol in TRPM8-expressing cutaneous afferent fibers}

Our results give raise to a model of channel recruitment in which static TRPM8 channels located at the PM raise $\left[\mathrm{Ca}^{2+}\right]_{\mathrm{i}}$ once activated by menthol, leading to the stabilization of nearby TRPM8-containing vesicles, originating a sensitized cellular response (Fig. 7). However, up to here, our study was performed on transfected cells at room temperature. Well aware that (1) nonnative levels of expression may originate unrealistic responses, (2) TRPM8 channels display a fine-tuned sensitivity to cold temperatures (McKemy et al., 2002; Brauchi et al., 2004), and (3) taking into account the fact that temperature has a tremendous influence on neurosecretion, we realized that these factors represent a technical shortcoming, potentially limiting the physiological relevance of our observations. To surmount this limitation, we performed electrophysiological recordings on intact fiber types in the skin expressing functional TRPM8 (i.e., CMC fibers and CC fibers) (Zimmermann et al., 2009, 2011; Vetter et al., 2013), to validate the significance of our findings in cold temperature sensing. If our hypothesis holds, we should be able to detect 
A

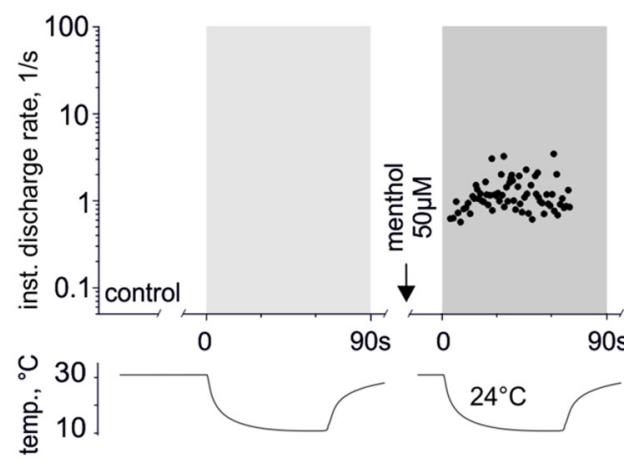

C

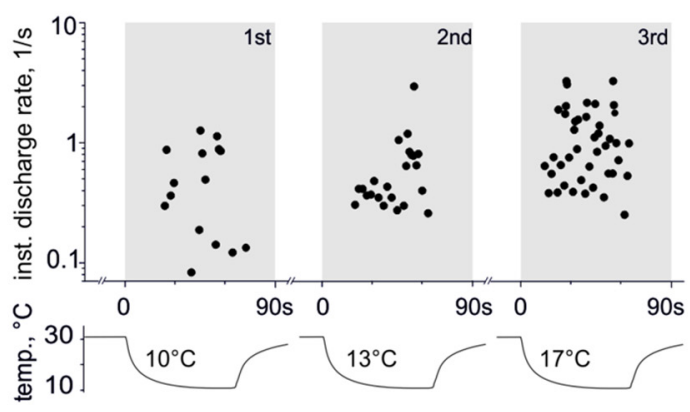

$\mathbf{F}$
B

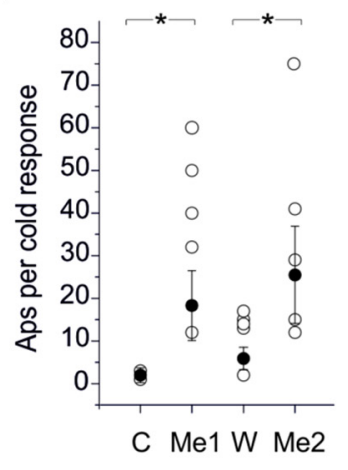

E

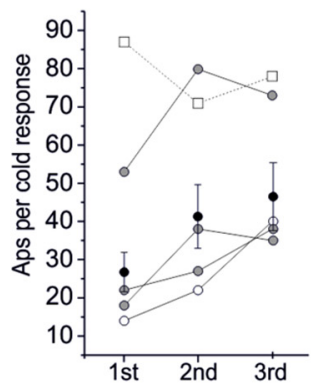

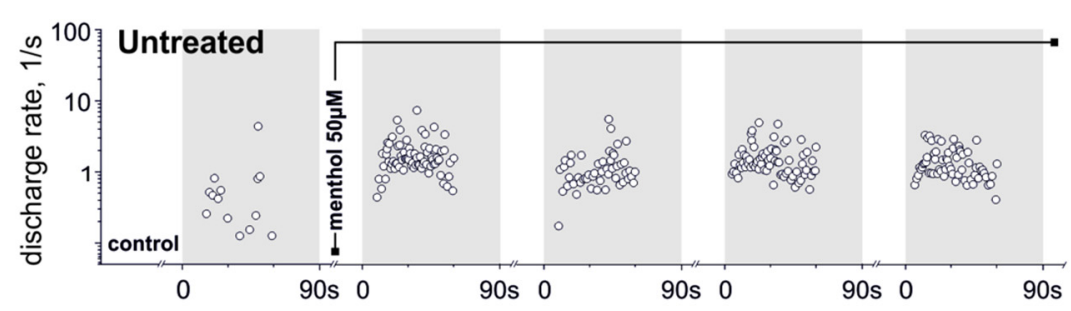

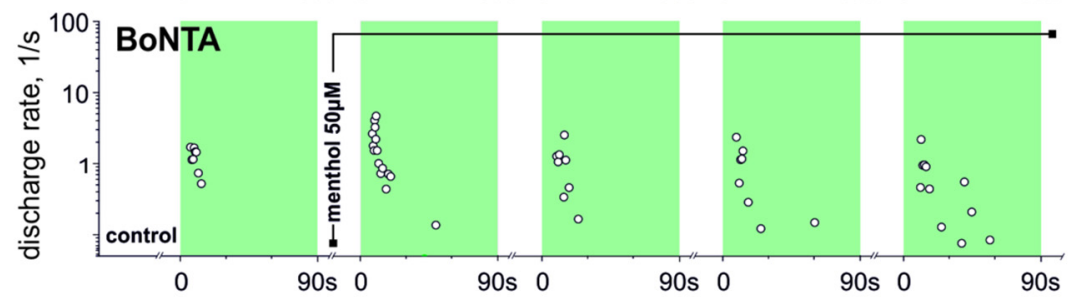

G
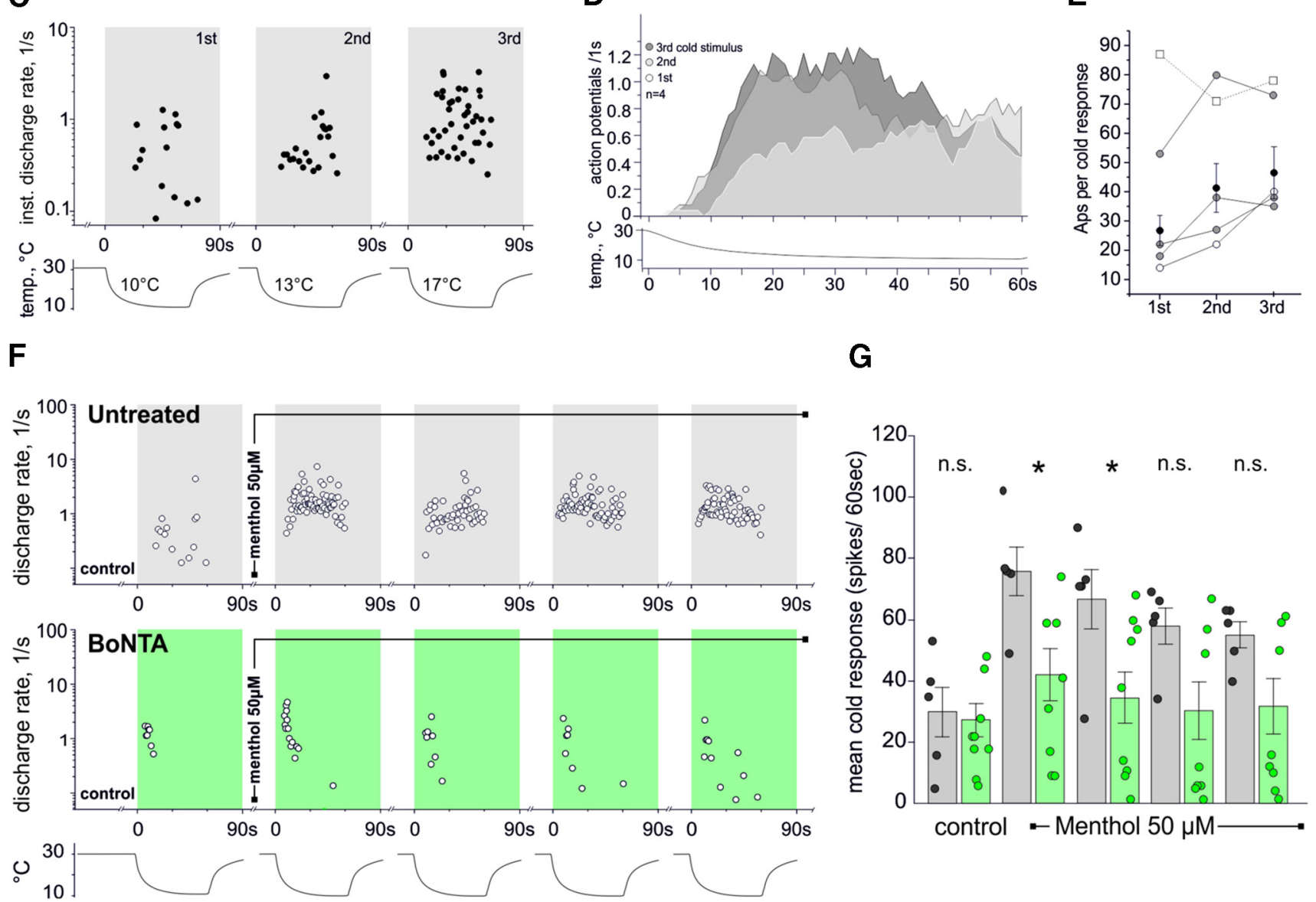

Figure 8. Agonist exposure increases cold sensitivity in CMC fibers and inhibition of vesicle exocytosis with BoNTA leads to increased adaptation of TRPM8-mediated responses. $\boldsymbol{A}$, Original recording from a temperature-insensitive mechanosensitive ( fiber recorded from the saphenous-nerve innervation territory of a $\mathrm{C} 57 \mathrm{BL} / 6 \mathrm{mouse}$. Instantaneous discharge rates in response to repeated menthol application $(50$ and $500 \mu \mathrm{m}$ ) and subsequent cooling of the receptive field are shown. Menthol produces de novo, partly reversible and reproducible sensitization to cold (interstimulus interval and drug wash-in $240 \mathrm{~s}$ ). Bottom, Time course of cold stimulus and temperature thresholds of activation. $\boldsymbol{B}$, Quantification of the menthol effect on cold sensitization as increase in response magnitude (action potentials (APs) per 60 s cold stimulus; $n=5$ ). Control cold stimulus marked with " $C$," "Me1," and "Me2": $50 \mu \mathrm{m}$ menthol application to receptive field; "W": drug wash-off ( $p=0.04$, Wilcoxon matched pairs test). $(-\boldsymbol{E}$, Repeated cold stimulation can increase cold response of menthol-sensitive cold nociceptors. $\boldsymbol{C}, \boldsymbol{D}$, Original recording from a CMC fiber showing instantaneous discharge rates in response to repeated $60 \mathrm{~s}$ cooling pulses $(\boldsymbol{C})$ and averaged responses of 4 fibers $(\boldsymbol{D})$. Repeated activation of the fiber by cold increased each subsequent response to cooling. Bottom, Time course of cold stimulus and temperature thresholds of activation. Interstimulus interval 3-4 min. $\boldsymbol{E}$, Magnitude of consecutive cold responses counted as action potentials (APs) per $60 \mathrm{~s}$ cold stimulus. CMC fibers with large cold response (white square, dashed line) desensitize. Gray circles represent individual data points. Black circles represent data points with SEM (mean of 4 fibers). Open white circles represent recording plotted in $\mathbf{C}$. $\boldsymbol{F}, \mathbf{G}$, BoNTA pretreatment prevents menthol-induced sensitization to cooling in most CMC fibers. $\boldsymbol{F}$, Original traces of CMC fibers recorded from (top) an untreated C57BL6 mouse skin-nerve preparation and (bottom) from a BoNTA-pretreated skin shown as instantaneous discharge rates in response to a $60 \mathrm{~s}$ cooling stimulus. Menthol $50 \mu \mathrm{m}$ was present throughout cold stimuli 2-5. Bottom, Temperature time course. G, Bar chart illustrating average cold responses (amount of action potentials per cold stimulus of $60 \mathrm{~s}$ ) of (MC fibers from untreated skins (gray, $n=5$ ) and BoNTA-treated skins (green, $n=9$ ). Circles represent individual data points. The majority (6 of 9) of CMC fibers from BoNTA-pretreated skins showed poor cold sensitization after menthol treatment. Interstimulus interval $180-240 \mathrm{~s} .{ }^{*} p<0.05$ (Mann-Whitney $U$ test). 
A

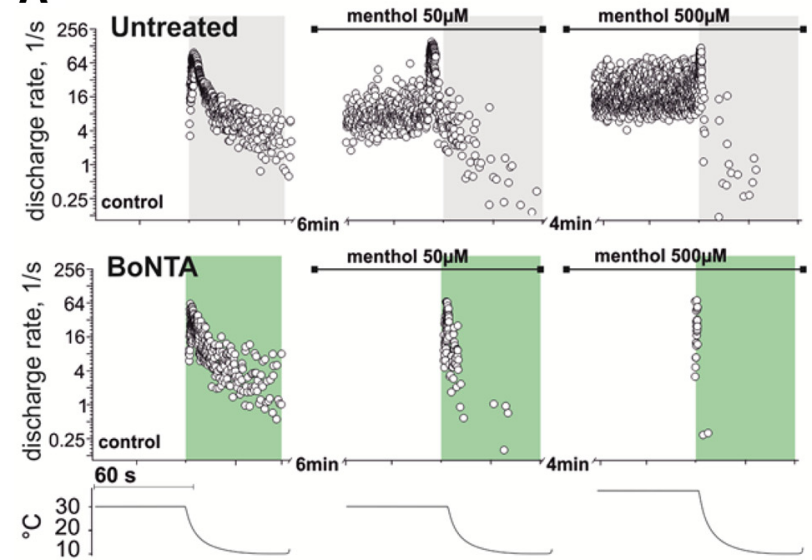

в
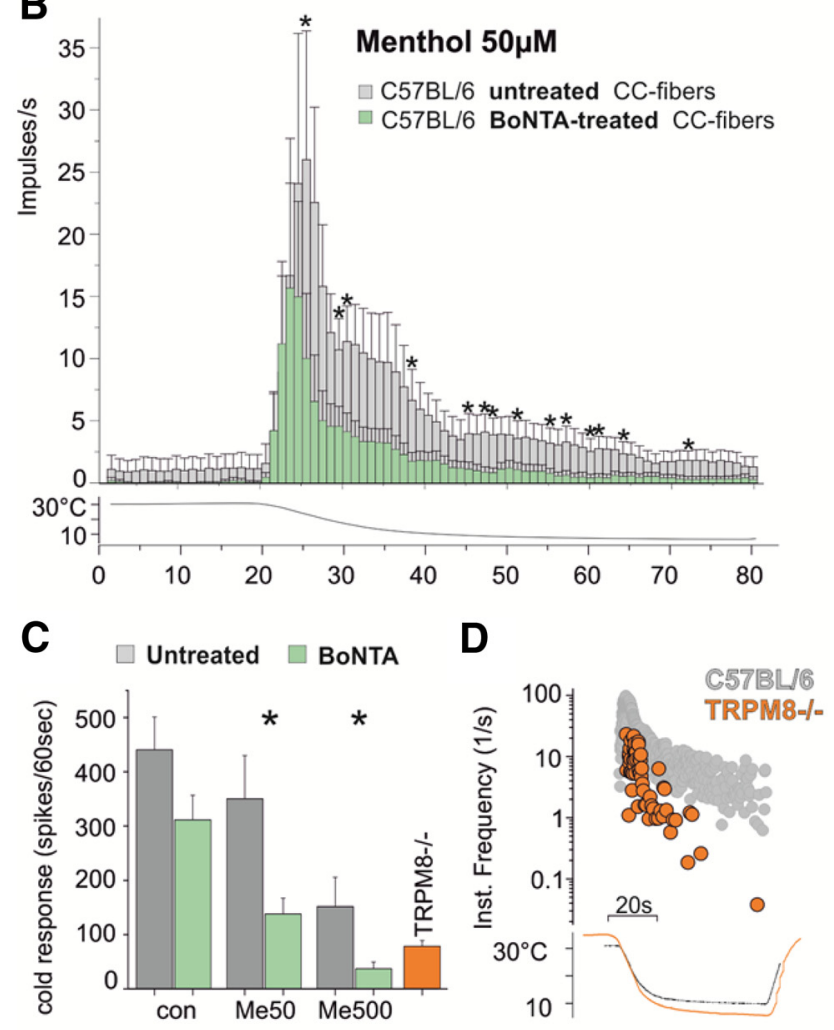

\section{E}

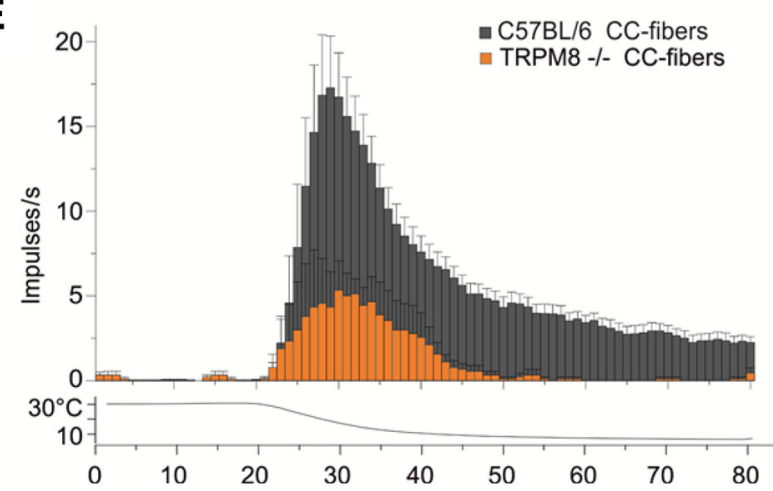

Figure 9. Menthol increases adaptation in BoNTA-pretreated monomodal cold receptors similar to coding deficits observed in TRPM8-deficient CC fibers. A, Original traces of CC fibers recorded from an untreated C57BL6 mouse skin-nerve preparation (top) and from a BoNTApretreated skin (bottom) shown as instantaneous discharge rates in response to a $60 \mathrm{~s}$ cooling correlates of the described traffic-mediated effects in the coldsensing nerve endings, like agonist-dependent sensitization of the TRPM8-mediated responses and signs of their desensitization following agonist activation (Reid et al., 2002; Rohacs et al., 2005; Latorre et al., 2011). Measuring cold- and menthol-activated propagated action potentials directly from intact endings of $\mathrm{CM}$ and $\mathrm{CMC}$ fibers with the skin-nerve preparation (Zimmermann et al., 2009), we found that acute menthol stimulation can unveil a large cold response in otherwise temperature-insensitive multimodal terminals (Fig. $8 A, B$ ). It is likely that a shift in temperature-dependent gating contributes to this phenomenon, but also an increase in TRPM8-channel density at the PM after menthol stimulation of the receptive field seems plausible. In addition, we found, in CMC fibers, that repetitive cooling without the presence of chemical agonists suffices to increase the response to consecutive cold stimulation up to a certain extent; each subsequent of three cold responses yielded increased numbers of action potentials discharged $(26.8,41.8$, and $46.5 \mathrm{APs}$ per $60 \mathrm{~s}$ cold response, $n=4 ; p=0.003, t$ test first vs third response) and peak firing rates $(3.2,4.0$, and $4.9 \mathrm{AP} / 1 \mathrm{~s}, n=4$, no significance) (Fig. 8C-E).

Because of its well-known capacity and specificity for inhibiting vesicle exocytosis, we used BoNTA (Wheeler and Smith, 2013) to investigate the contribution of trafficking to the cold response and menthol sensitization. To allow for BoNTA to reach its target site in the nerve terminals, preparations were incubated with several units of BoNTA (see Materials and Methods) and refrigerated for a minimum of $2.5 \mathrm{~h}$ after preparation. Recording CMC fibers from treated skins, we observed that CMC fibers had normal cold responses, but the majority ( 6 of 9) showed unusually poor sensitization to cold following menthol treatment ( $55 \%$ of the untreated fibers' response magnitude; Fig. $8 G, F$ ). In addition, repeated cold stimulation in the presence of menthol led to a rapid decline of the cold response to control values (Fig. 8G,F). We next tested the influence of BoNTA treatment on the responses of monomodal cold receptors (CC fibers), another menthol-sensitive fiber type. CC fibers frequency-encode temperature, show phasic activity upon cooling, and exhibit 20 -fold larger cold responses than CMC fibers (Zimmermann et al., 2011). The fibers were identified by their high-frequency firing in response to passing a piece of ice cube slowly and close to the surface of the corium. Pretreatment with BoNTA seemed not to affect the magnitude of the cold response (Fig. $9 A-C$ ), but it clearly increased adaptation of the CC fibers after treatment with menthol at both 50 and $500 \mu \mathrm{M}$ (Fig. 9A-C). This finding points toward increased desensitization of functional TRPM8 receptors. We next characterized the properties of CC fibers in TRPM8-

stimulus. Menthol $50 \mu$ m was present throughout a second cold stimulus, and menthol $500 \mu \mathrm{M}$ throughout the third stimulus. Bottom, Temperature time course. $\boldsymbol{B}$, Averaged histogram in bins of $1 / \mathrm{s}$ illustrating the effect of menthol $50 \mu \mathrm{m}$ on the cold response of $\mathrm{CC}$ fibers from untreated skins (gray, $n=8(50 \mu \mathrm{m})$ and $7(500 \mu \mathrm{M})$ ) and BoNTA-treated skins (green, $n=9$ $(50 \mu \mathrm{M})$ and $8(500 \mu \mathrm{M}))$. After menthol treatment, BoNTA-treated $C($ fibers show increased adaptation, illustrated in reduced dynamic and static responses. ${ }^{*} p<0.05$ (Mann-Whitney $U$ test). C, Bar charts aligning magnitude of cold response from (C fibers of untreated (gray), BoNTA-pretreated (green), and untreated TRPM8-deficient skins (orange). ${ }^{*} p<0.05$ (MannWhitney $U$ test). $\boldsymbol{D}$, Original recording from a TRPM ${ }^{-1-}$ CC fiber (orange) shown as instantaneous discharge rate with static and dynamic coding deficits and rapid adaptation during $60 \mathrm{~s}$ cooling. Gray represents (57BL6 CC fiber (from A). Bottom, Temperature time course. E, Averaged histogram in bins of 1 s summarizing the cold responses of CC fibers recorded from $\mathrm{C57 \textrm {BL } / 6}$ mice and TRPM8-deficient mice in response to cooling from $30^{\circ} \mathrm{C}$ to $10^{\circ} \mathrm{C}$. Gray columns represent C57BL/6 CC fibers $(n=17)$. Green columns represent TRPM $8^{-1-}$ CC fibers $(n=3)$. 
deficient skins. Lack of TRPM8 proved to result in strong tachyphylaxis to repeated stimulation with cold; therefore, only few fibers could be isolated and recorded after stimulation with ice cubes. The recorded TRPM8-deficient fibers exhibit important static and dynamic coding deficits as illustrated in Figure 9D, E. Comparing the responses of the menthol-activated BoNTApretreated CC fibers and the TRPM8-deficient CC fibers, it appears as if sustained activation of TRPM8 typically entails a progressive depletion of functional TRPM8 in the membrane accompanied by simultaneous insertion of new, nondesensitized channels, which secures sustained responsiveness to cold.

Our data provide evidence that a trafficking-mediated mechanism contributes to a sensitized, steady cold response in coldsensing fibers in the skin and that trafficking of TRPM8 in vesicles counteracts the known desensitization of TRPM8 following activation (Rohacs et al., 2005). Together, our results at the molecular and cellular level may explain the observed effects of BoNT/A in the intact sensory nerve terminals (Wheeler and Smith, 2013).

\section{Discussion}

Eukaryotic cells have relatively large cell bodies, and vesicular trafficking is a mechanism used to deal with the intrinsic unspecificity of diffusion-based signaling. Largely depending on ion binding events, calcium-dependent vesicular fusion allows for the rapid control of PM receptors and ion channels (Sudhof, 2004; Neher and Sakaba, 2008). In this process, the main role of $\mathrm{Ca}^{2+}$ is to trigger the last steps of vesicle fusion with the PM (Sudhof, 2004). However, calcium ions not only promote fusion, they also participate in the modulation of the coupling between exocytosis and compensatory endocytosis during the postfusion period (Vogel et al., 1999; Wu et al., 2009; Miklavc et al., 2011). Therefore, localized $\mathrm{Ca}^{2+}$ influx may not only allow for the rapid fusion of vesicles containing channels but also contribute to the stabilization of the vesicle once fused. In this context, the role of restricted calcium in the modulation of prefusion and postfusion events defining vesicular turnover is quite attractive (Miklavc and Frick, 2011). Special attention should be paid to local calcium changes in the vicinity of calcium-permeable channels located at the PM. This is because their activation may regulate the postfusion dynamics of individual vesicles and the fate of their cargo (Smith et al., 2000; Yao et al., 2009; Miklavc et al., 2010, 2011).

In this study, we show and describe agonist-induced changes in the dynamics of TRPM8-containing vesicles. Our work indicates that menthol stimulation modifies vesicle diffusion, induces a transient vesicle recruitment to the membrane, and stabilizes the fused mode allowing for a rapid modulation of the number of active channels in the PM. Interestingly, but not surprisingly, such modulation is calcium dependent and TRPM8's activity is sufficient to support its own recruitment. In other words, TRPM8 can modulate the gain of its own sensory circuit using positive feedback. It is known that gain circuits based on feed forward amplifiers often collapse because they easily become unstable and oscillate. For this reason, we picture that the mechanism unveiled here is limited, can be easily saturated, and has to be finely tuned. Indeed, we observed that the initial mentholdependent recruitment is strong but transitory, lasting hundreds of seconds, then, even in the presence of menthol, the number of membrane-associated channels starts to diminish. A secondary control mechanism might be provided by the calcium-dependent desensitization of the menthol response, a mechanism that might overlap depending on intracellular calcium dynamics (McKemy et al., 2002; Reid et al., 2002; Latorre et al., 2011). Both mechanisms, recruitment to the membrane and calcium-dependent de- sensitization, may converge to regulate the native responses observed in the skin nerve recordings (Figs. 8 and 9). Additionally, the feed forward mechanism grants the insertion of nondesensitized channels, allowing a sustained response before desensitization of the nerve terminal. In agreement whit this line of reasoning, BoNTA treatments cause an increase on CC fiber adaptation. A similar mechanism, working on the second to minutes time scale, has been observed for the case of AMPA receptors. In this case, trafficking plays an important role in the control of fast synaptic transmission by providing a set of nondesensitized receptors to the postsynaptic density, regulating the recovery from postsynaptic depression (Heine et al., 2008).

Our current view is that TRPM8 channels, expressed in the membranes of nerve endings, generate a localized $\mathrm{Ca}^{2+}$ signal in response to agonists or temperature allowing for the rapid recruitment of a vesicular pool. This is accomplished by both promoting fusion and improving the stabilization of the vesicle (helped by a still unknown mechanism), ultimately altering the density together with the time vesicles reside at the membrane. Such stabilization of the fused vesicle increases the number of active channels having access to the extracellular solution via the lumen of the fused vesicle, thereby permitting these vesicleassociated channels to contribute to the membrane currents recorded by whole-cell voltage clamp (Figs. 4 and Fig. 7). This positive feedback loop helps the cell reach the depolarization threshold producing a rapid increase in neuronal discharge. As suggested by our recordings on intact nerve-skin circuit, the positive feedback mechanism for exocytosis described here should work only until a certain stable higher level of TRPM8 is present in the membrane, then endocytosis should be favored to set the new steady state. This is what we observed in the fibers using cooling as TRPM8 agonist: the second cold response is only larger when the initial response was moderate or absent (Fig. 8C-E).

Thus, our findings support a model in which postfusion $\mathrm{Ca}^{2+}$ entry via $\mathrm{Ca}^{2+}$-permeable channels, expressed on mobile vesicles, plays a role in regulated exocytosis and cellular excitability (Thorn, 2009; Miklavc and Frick, 2011). There are interesting outstanding questions that arise from our observations as other TRPM channels have been shown to associate with exocytic vesicles, including TRPM1 (Oancea et al., 2009), TRPM2 (Lange et al., 2009), TRPM4 (Crnich et al., 2010), and TRPM7 (Brauchi et al., 2008), and it is an open question as to whether this mechanism is conserved among TRPM channels. Equally intriguing is the nature of the vesicles transporting TRPM8 channels and the possibility that specific TRPM8-associated proteins help to modulate the calciumdependent stabilization of TRPM8-containing vesicles.

\section{References}

Alvarez O, Gonzalez C, Latorre R (2002) Counting channels: a tutorial guide on ion channel fluctuation analysis. Adv Physiol Educ 26:327-341. CrossRef Medline

Bar-On D, Winter U, Nachliel E, Gutman M, Fasshauer D, Lang T, Ashery U (2008) Imaging the assembly and disassembly kinetics of cis-SNARE complexes on native plasma membranes. FEBS Lett 582:3563-3568. CrossRef Medline

Bautista DM, Siemens J, Glazer JM, Tsuruda PR, Basbaum AI, Stucky CL, Jordt SE, Julius D (2007) The menthol receptor TRPM8 is the principal detector of environmental cold. Nature 488:204-208. CrossRef Medline

Belmonte C, Brock JA, Viana F (2009) Converting cold into pain. Exp Brain Res 196:13-30. CrossRef Medline

Bender FL, Mederos Y, Schnitzler M, Li Y, Ji A, Weihe E, Gudermann T, Schäfer MK (2005) The temperature-sensitive ion channel TRPV2 is endogenously expressed and functional in the primary sensory cell line F-11. Cell Physiol Biochem 15:183-194. CrossRef Medline

Bezzerides VJ, Ramsey IS, Kotecha S, Greka A, Clapham DE (2004) Rapid 
vesicular translocation and insertion of TRP channels. Nat Cell Biol 6:709-720. CrossRef Medline

Brauchi S, Orio P, Latorre R (2004) Clues to understanding cold sensation: thermodynamics and electrophysiological analysis of the cold receptor TRPM8. Proc Natl Acad Sci U S A 101:15494-15499. CrossRef Medline

Brauchi S, Krapivinsky G, Krapivinsky L, Clapham DE (2008) TRPM7 facilitates cholinergic vesicle fusion with the plasma membrane. Proc Natl Acad Sci U S A 105:8304-8308. CrossRef Medline

Cayouette S, Boulay G (2007) Intracellular trafficking of TRP channels. Cell Calcium 42:225-232. CrossRef Medline

Cayouette S, Lussier MP, Mathieu EL, Bousquet SM, Boulay G (2004) Exocytotic insertion of TRPC6 channel into the plasma membrane upon Gq proteincoupled receptor activation. J Biol Chem 279:7241-7246. CrossRef Medline

Clapham DE (2007) Calcium signaling. Cell 131:1047-1058. CrossRef Medline Crnich R, Amberg GC, Leo MD, Gonzales AL, Tamkun MM, Jaggar JH, Earley S (2010) Vasoconstriction resulting from dynamic membrane trafficking of TRPM4 in vascular smooth muscle cells. Am J Physiol Cell Physiol 299:C682-C694. CrossRef Medline

Dhaka A, Murray AN, Mathur J, Earley TJ, Petrus MJ, Patapoutian A (2007) TRPM8 is required for cold sensation in mice. Neuron 54:371-378. CrossRef Medline

Fernández JA, Skryma R, Bidaux G, Magleby KL, Scholfield CN, McGeown JG, Prevarskaya N, Zholos AV (2011) Voltage- and cold-dependent gating of single TRPM8 ion channels. J Gen Physiol 137:173-195. CrossRef Medline

Flanagan MD, Lin S (1980) Cytochalasins block actin filament elongation by binding to high affinity sites associated with F-actin. J Biol Chem 255:835-838. Medline

Heine M, Groc L, Frischknecht R, Béïque JC, Lounis B, Rumbaugh G, Huganir RL, Cognet L, Choquet D (2008) Surface mobility of postsynaptic AMPARs tunes synaptic transmission. Science 320:201-205. CrossRef Medline

Kanzaki M, Zhang YQ, Mashima H, Li L, Shibata H, Kojima I (1999) Translocation of a calcium-permeable cation channel induced by insulin-like growth factor-I. Nat Cell Biol 1:165-170. CrossRef Medline

Lambers TT, Oancea E, de Groot T, Topala CN, Hoenderop JG, Bindels RJ (2007) Extracellular pH dynamically controls cell surface delivery of functional TRPV5 channels. Mol Cell Biol 27:1486-1494. CrossRef Medline

Lange I, Yamamoto S, Partida-Sanchez S, Mori Y, Fleig A, Penner R (2009) TRPM2 functions as a lysosomal $\mathrm{Ca}^{2+}$-release channel in beta cells. Sci Signal 2:ra23. CrossRef Medline

Latorre R, Brauchi S, Madrid R, Orio P (2011) A cool channel in cold transduction. Physiology 26:273-285. CrossRef Medline

McKemy DD, Neuhausser WM, Julius D (2002) Identification of a cold receptor reveals a general role for TRP channels in thermosensation. Nature 416:52-58. CrossRef Medline

Miklavc P, Frick M (2011) Vesicular calcium channels as regulators of the exocytotic post-fusion phase. Commun Integr Biol 4:796-798. CrossRef Medline

Miklavc P, Frick M, Wittekindt OH, Haller T, Dietl P (2010) Fusionactivated $\mathrm{Ca}(2+)$ entry: an "active zone" of elevated $\mathrm{Ca}(2+)$ during the postfusion stage of lamellar body exocytosis in rat type II pneumocytes. PLoS One 5:e10982. CrossRef Medline

Morenilla-Palao C, Pertusa M, Meseguer V, Cabedo H, Viana F (2009) Lipid raft segregation modulates TRPM8 channel activity. J Biol Chem 284:9215-9224. CrossRef Medline

Neher E, Sakaba T (2008) Multiple roles of calcium ions in the regulation of neurotransmitter release. Neuron 59:861-872. CrossRef Medline

Oancea E, Vriens J, Brauchi S, Jun J, Splawski I, Clapham DE (2009) TRPM1 forms ion channels associated with melanin content in melanocytes. Sci Signal 2:ra21. CrossRef Medline

Oancea E, Wolfe JT, Clapham DE (2006) Functional TRPM7 channels accumulate at the plasma membrane in response to fluid flow. Circ Res 98:245-253. CrossRef Medline

Pertusa M, Madrid R, Morenilla-Palao C, Belmonte C, Viana F (2012) $\mathrm{N}$-glycosylation of TRPM8 ion channels modulates temperature sensitivity of cold thermoreceptor neurons. J Biol Chem 287:18218-18229. CrossRef Medline

Qian H, Sheetz MP, Elson EL (1991) Single particle tracking: analysis of diffusion and flow in two-dimensional systems. Biophys J 60:910-921. CrossRef Medline

Reid G, Babes A, Pluteanu F (2002) A cold- and menthol-activated current in rat dorsal root ganglion neurones: properties and role in cold transduction. J Physiol 545:595-614. CrossRef Medline

Rohács T, Lopes CM, Michailidis I, Logothetis DE (2005) PI(4,5)P2 regu- lates the activation and desensitization of TRPM8 channels through the TRP domain. Nat Neurosci 8:626-634. CrossRef Medline

Schmidt M, Dubin AE, Petrus MJ, Earley TJ, Patapoutian A (2009) Nociceptive signals induce trafficking of TRPA1 to the plasma membrane. Neuron 64:498-509. CrossRef Medline

Shapovalov G, Gkika D, Devilliers M, Kondratskyi A, Gordienko D, Busserolles J, Bokhobza A, Eschalier A, Skryma R, Prevarskaya N (2013) Opiates modulate thermosensation by internalizing cold receptor TRPM8. Cell Rep 4:504-515. CrossRef Medline

Smith RM, Baibakov B, Ikebuchi Y, White BH, Lambert NA, Kaczmarek LK, Vogel SS (2000) Exocytotic insertion of calcium channels constrains compensatory endocytosis to sites of exocytosis. J Cell Biol 148:755-767. CrossRef Medline

Stein AT, Ufret-Vincenty CA, Hua L, Santana LF, Gordon SE (2006) Phosphoinositide 3-kinase binds to TRPV1 and mediates NGF-stimulated TRPV1 trafficking to the plasma membrane. J Gen Physiol 128:509-522. CrossRef Medline

Sudhof TC (2004) The synaptic vesicle cycle. Annu Rev Neurosci 27:509_ 547. CrossRef Medline

Thorn P (2009) New insights into the control of secretion. Commun Integr Biol 2:315-317. CrossRef Medline

Tilney LG, Connelly PS, Portnoy DA (1990) Actin filament nucleation by the bacterial pathogen, Listeria monocytogenes. J Cell Biol 111:2979-2988. CrossRef Medline

Torgersen ML, Skretting G, van Deurs B, Sandvig K (2001) Internalization of cholera toxin by different endocytic mechanisms. J Cell Sci 114:37373747. Medline

Toro CA, Arias LA, Brauchi S (2011) Sub-cellular distribution and translocation of TRP channels. Curr Pharm Biotechnol 12:12-23. CrossRef Medline

Valentijn KM, Gumkowski FD, Jamieson JD (1999) The subapical actin cytoskeleton regulates secretion and membrane retrieval in pancreatic acinar cells. J Cell Sci 112:81-96. Medline

Valenzano KJ, Grant ER, Wu G, Hachicha M, Schmid L, Tafesse L, Sun Q, Rotshteyn Y, Francis J, Limberis J, Malik S, Whittemore ER, Hodges D (2003) $\mathrm{N}$-(4-tertiarybutylphenyl)-4-(3-chloropyridin-2-yl)tetrahydropyrazine$1(2 \mathrm{H})$-carbox-amide (BCTC), a novel, orally effective vanilloid receptor 1 antagonist with analgesic properties: I. In vitro characterization and pharmacokinetic properties. J Pharmacol Exp Ther 306:377-386. CrossRef Medline

Veliz LA, Toro CA, Vivar JP, Arias LA, Villegas J, Castro MA, Brauchi S (2010) Near-membrane dynamics and capture of TRPM8 channels within transient confinement domains. PLoS One 5:e13290. CrossRef Medline

Vetter I, Hein A, Sattler S, Hessler S, Touska F, Bressan E, Parra A, Hager U, Leffler A, Boukalova S, Nissen M, Lewis RJ, Belmonte C, Alzheimer C, Huth T, Vlachova V, Reeh PW, Zimmermann K (2013) Amplified cold transduction in native nociceptors by M-channel inhibition. J Neurosci 33:16627-16641. CrossRef Medline

Vogel SS, Smith RM, Baibakov B, Ikebuchi Y, Lambert NA (1999) Calcium influx is required for endocytotic membrane retrieval. Proc Natl Acad Sci U S A 96:5019-5024. CrossRef Medline

Wheeler A, Smith HS (2013) Botulinum toxins: mechanisms of action, antinociception and clinical applications. Toxicology 306:124-146. CrossRef Medline

Wu XS, McNeil BD, Xu J, Fan J, Xue L, Melicoff E, Adachi R, Bai L, Wu LG (2009) $\mathrm{Ca}(2+)$ and calmodulin initiate all forms of endocytosis during depolarization at a nerve terminal. Nat Neurosci 12:1003-1010. CrossRef Medline

Yao CK, Lin YQ, Ly CV, Ohyama T, Haueter CM, Moiseenkova-Bell VY, Wensel TG, Bellen HJ (2009) A synaptic vesicle-associated $\mathrm{Ca}^{2+}$ channel promotes endocytosis and couples exocytosis to endocytosis. Cell 138:947-960. CrossRef Medline

Zhang X, Huang J, McNaughton PA (2005) NGF rapidly increases membrane expression of TRPV1 heat-gated ion channels. EMBO J 24:42114223. CrossRef Medline

Zimmermann K, Hein A, Hager U, Kaczmarek JS, Turnquist BP, Clapham DE, Reeh PW (2009) Phenotyping sensory nerve endings in vitro in the mouse. Nat Protoc 4:174-196. CrossRef Medline

Zimmermann K, Lennerz JK, Hein A, Link AS, Kaczmarek JS, Delling M, Uysal S, Pfeifer JD, Riccio A, Clapham DE (2011) Transient receptor potential cation channel, subfamily C, member 5 (TRPC5) is a coldtransducer in the peripheral nervous system. Proc Natl Acad Sci U S A 108:18114-18119. CrossRef Medline 